\title{
Broadly neutralizing antibodies suppress post-transcytosis HIV-1 infectivity
}

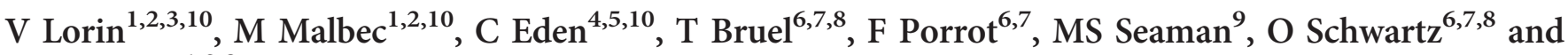 \\ H Mouquet ${ }^{1,2,8}$
}

Broadly neutralizing antibodies (bNAbs) offer promising opportunities for preventing HIV-1 infection in humans. Immunoprophylaxis with potent bNAbs efficiently protects non-human primates from mucosal transmission even after repeated challenges. However, the precise mechanisms of bNAb-mediated viral inhibition in mucosal tissues are currently unknown. Here, we show that immunoglobulin $(\mathrm{Ig}) \mathrm{G}$ and $\operatorname{lgA}$ bNAbs do not interfere with the endocytic transport of HIV-1 across epithelial cells, a process referred to as transcytosis. Instead, both viruses and antibodies are translocated to the basal pole of epithelial cells, possibly in the form of an immune complex. Importantly, as opposed to free virions, viral particles bound by bNAbs are no longer infectious after transepithelial transit. Post-transcytosis neutralization activity of bNAbs displays comparable inhibitory concentrations as those measured in classical neutralization assays. Thus, bNAbs do not block the transport of incoming HIV-1 viruses across the mucosal epithelium but rather neutralize the transcytosed virions, highlighting their efficient prophylactic and protective activity in vivo.

\section{INTRODUCTION}

Genitorectal mucosal surfaces are frequent portals of entry for HIV-1. ${ }^{1,2}$ Mucosal transmission of HIV-1 is mediated by virusinfected cells or by free infectious virions and is a rapid process, with viral spread to draining lymph nodes occurring within a few days. ${ }^{3,4}$ Viral dissemination necessitates the passage of viruses across the mucosal epithelium, and the subsequent infection of subepithelial dendritic cells, macrophages, or T cells. ${ }^{4}$ Transport of HIV-1 through intact mucosal tissues can be mediated by $\mathrm{M}$ cells in pseudostratified epithelium of the intestine, ${ }^{5}$ and by dendritic cells sampling antigens in the lumen. ${ }^{6}$ Moreover, intraepithelial $\mathrm{T}$ lymphocytes and Langerhans cells constitute primary HIV-1 target cells that can later on efficiently transfer viruses to susceptible cells in subepithelial stromal tissues. ${ }^{7,8}$ Lastly, a process called transcytosis is thought to be one of the major mechanisms involved in HIV-1 translocation across the single-layer columnar epithelium found in the vaginal endocervix, colon, and rectum. ${ }^{9}$ Transcytosis is a transcellular transport of cargo molecules from the apical to the basal end of polarized epithelia via endocytic vesicles. ${ }^{9}$
Antibodies, particularly locally produced secretory immunoglobulin (Ig)A and transudated IgG are well known to protect mucosal tissues from invading pathogens. ${ }^{10}$ In this regard, there is suggestive evidence that antibodies might block HIV-1 transcytosis at mucosal sites. ${ }^{11} \mathrm{HIV}$-infected individuals and more interestingly, HIV-exposed individuals that are persistently seronegative (HEPS) can develop mucosal HIVspecific IgAs capable of blocking viral transcytosis through epithelial cells. ${ }^{12-14}$ In addition, monoclonal IgA antibodies against HIV-1 envelope protein gp160 have been shown to inhibit intracellular HIV replication and HIV transcytosis. ${ }^{15,16}$ However, whether HIV-specific antibodies actually inhibit viral transcytosis is still debated. ${ }^{11}$

Several years after co-evolution with diversifying viruses, B-cell maturation can lead, in rare infected individuals, to the development of cross-reactive antibodies called broadly neutralizing antibodies (bNAbs) capable of neutralizing most of the known HIV-1 strains. ${ }^{11}$ Over the past decade, the most potent and broad HIV-1 bNAbs, categorized as "next generation", have been isolated and characterized thereby

${ }^{1}$ Laboratory of Humoral Response to Pathogens, Department of Immunology, Institut Pasteur, Paris, France. ${ }^{2}$ INSERM U1222, Paris, France. ${ }^{3}$ Université Paris Diderot, Sorbonne Paris Cité, Paris, France. ${ }^{4}$ Laboratory of Molecular Immunology, The Rockefeller University, New York City, New York, USA. ${ }^{5}$ Icahn School of Medicine at Mount Sinai, New York City, New York, USA. ${ }^{6}$ Virus \& Immunity Unit, Department of Virology, Institut Pasteur, Paris, France. ${ }^{7}$ CNRS URA3015, Paris, France. ${ }^{8}$ Vaccine Research Institute, Créteil, France and ${ }^{9}$ Beth Israel Deaconess Medical Center, Boston, Massachusetts, USA. Correspondence: H Mouquet (hugo.mouquet@pasteur.fr)

${ }^{10}$ These authors contributed equally to this work. 
allowing the mapping of conserved and functionally critical epitopes on the HIV-1 surface envelope glycoprotein gp160. Five of these pan-neutralizing epitopes named "supersites of vulnerability" have been identified so far: the CD4 binding site, $\mathrm{N}$-glycan-associated epitopes on the V1/V2 loops and the V3 loop, the membrane proximal external region (MPER) on gp41, and the $N$-glycan-associated gp120/gp41 bridging region. ${ }^{11}$ Passive immunotherapy with potent HIV-1 bNAbs has been shown to protect from infection in animal models, ${ }^{17-21}$ particularly from mucosal infection even after repeated virus challenges. ${ }^{22-28}$ In addition, passive administration of a single dose of $\mathrm{CD} 4$ binding site-specific bNAbs can substantially reduce viraemia in infected humans. ${ }^{29,30}$ Potency of the inhibitory activity against cell free and cell-to-cell infection, ${ }^{17,31}$ as well as Fc-dependent effector function of bNAbs such as antibody-dependent cell-mediated cytotoxicity (ADCC), ${ }^{32}$ likely play critical roles for in vivo protection. ${ }^{33-36}$ But whether bNAbs are effective in in vivo models using mucosal challenges due to their ability to directly interfere with viral transcytosis and/or to decrease the infectivity of transcytosed viruses is not yet known.

Since successful HIV-1 vaccines would ideally elicit crossneutralizing antibodies capable of protecting mucosal tissues, it is thus important to understand the mechanisms allowing bNAbs to interfere with the mucosal transmission of HIV-1. A better comprehension of these mechanisms will also help optimize immunotherapy strategies to confer pre-exposure prophylaxis. In this study, we show that potent bNAbs were unable to block in vitro HIV-1 transcytosis, which we found to be independent of envelope glycoproteins, but efficiently inhibited the infectivity of the transcytosed virus. Their inhibitory activity was not dependent on the targeted epitopes and antibody sub-classes but directly correlated to in vitro potency for neutralizing cell-free viruses. These findings highlight the mechanisms involved in the potential prophylactic activity of HIV-1 bNAbs.

\section{RESULTS \\ IgA class-switched HIV-1 bNAbs maintain their binding specificities}

To test the activity of next generation HIV-1 bNAbs against viral transcytosis, we selected five of the most potent and broad antibodies. Two of them bind to the CD4 binding site, 3BNC117, and NIH45-46; ${ }^{37}$ PG16 $6^{38}$ and $10-1074^{39}$ react with $\mathrm{N}$-glycan-associated V1/V2- and V3-loop epitopes, respectively; and 10E8 recognizes the membrane proximal external region on the gp41 subunit. ${ }^{40}$ To directly compare the activity of IgG $v$ IgA immunoglobulins, we generated HIV-1 bNAbs as recombinant IgG1, IgA1, and IgA2 monoclonal antibodies (Supplementary Figure S1 online). ${ }^{41}$ To determine whether the IgA class-switching can preserve the original binding properties of IgG1 bNAbs, we tested monomeric IgA and IgG bNAbs' recognition of gp160 expressed by virus-infected cells or purified as a recombinant protein. Flow cytometry analysis showed that apart from 10E8, all IgG1, IgA1, and IgA2 bNAbs bound to MT4C5 lymphoblastoid T cells infected by the
NLAD8 viral strain, although a direct comparison between IgG and IgA molecules was not possible (due to the use of different secondary antibodies) (Figure 1a,b). IgA1 and IgA2 bNAbs recognized trimeric YU-2 gp140 antigen by enzyme-linked immunosorbent assay (ELISA) with the same binding profiles as their IgG counterparts (Figure 1c). Binding experiments performed by surface plasmon resonance (SPR) confirmed that IgAs have no substantial modifications of their relative affinities for YU-2 gp140 and gp120 proteins (Figure 1d). Finally, we could verify by ELISA binding analyses that anti-gp120 IgAs (except conformation-sensitive PG16) were still sensitive to specific mutations in bNAbs epitopes (Figure 1e, Supplementary Figure S2), and that 10E8 IgAs were highly reactive against the MPER peptide (Figure 1f). Thus, ex-vivo IgA-class switching of HIV-1 bNAbs does not appreciably modify their original binding and affinity for gp 160 .

\section{IgA HIV-1 bNAbs display IgG-equivalent viral inhibitory activities}

We then determined whether IgA bNAbs could recapitulate the antiviral properties of the original IgGs. To this end, we first measured the capacity of purified IgA1 and IgA2 antibodies to inhibit HIV-1 infection of TZM-bl cells using a panel of five selected viral strains. As expected from the ELISA data using YU-2 gp140 trimers as antigen, the in vitro neutralization activities of IgA1 and IgA2 bNAbs against YU-2 viruses were very similar to parental IgGs (Figure 2a). The four other selected viruses were neutralized by IgA bNAbs, with modest ( $\leq 2$-fold change) to more marked (up to sixfold change) differences depending on the antibody and viral strain when compared to IgGs (Figure 2b). These bNAbs, except 10E8, efficiently inhibit the cell-to-cell spread of HIV- $1 .{ }^{31}$ We thus evaluated the in vitro activity of HIV-1 IgA bNAbs against the cell-to-cell transmission of the CCR5-tropic (R5) HIV-1 strain, NLAD8, and compared it to historical data obtained with $\mathrm{IgGs}^{31}$ (Figure 2c-e). IgA1/IgA2 and IgG bNAbs exhibited comparable inhibitory activity against HIV-1 cell-to-cell spread (Figure 2e). Together, our data show that bNAbs expressed as IgA faithfully conserved their affinity for HIV-1 envelope trimers, and inhibitory activities against cell-free and cellassociated infection.

HIV-1 and antibody transport through polarized epithelial cell monolayers

To evaluate the activity of HIV-1 bNAbs against HIV-1 transcytosis, we first established an in vitro assay using the human endometrial adenocarcinoma cell line HEC-1A exposed to the HIV-1 strain NLAD8. In accordance with transepithelial electrical resistance (TER) measurements, HEC-1A cells in culture assembled in tight monolayers from day 5 until at least day 9 (Figure 3a). Epithelial monolayers were characterized by the formation of tight junctions with homogenous E-cadherin expression (Figure $\mathbf{3 b}$ ), and an absence of permeability to $40 \mathrm{kDa}$ diethylaminoethyl (DEAE) Dextran molecules across the lower chamber of the transwell system (Figure 3c). HIV-1 transcytosis was assayed at day 6, and showed that an average of $47 \%$ of the viral input passed through 
the porous membrane of the insert without cells and that $6.8 \%$ of the applied viral load vtranslocated across epithelial cell monolayers (Figure 3d).

HIV-1 transcytosis assessed in various human epithelial cell lines was previously shown to be independent of envelope glycoproteins. ${ }^{42-44}$ In the in vitro transcytosis assay developed here, we also found that envelope-deficient HIV-1 virions $(\Delta \mathrm{Env}-\mathrm{NL})$ translocated across HEC-1A epithelial monolayers comparably to wild-type NLAD8 virus (9.2\%, $P=0.93$ ) (Figure 3e). To determine whether antibodies could a
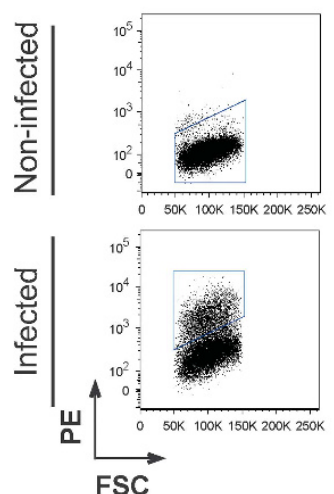

FSC
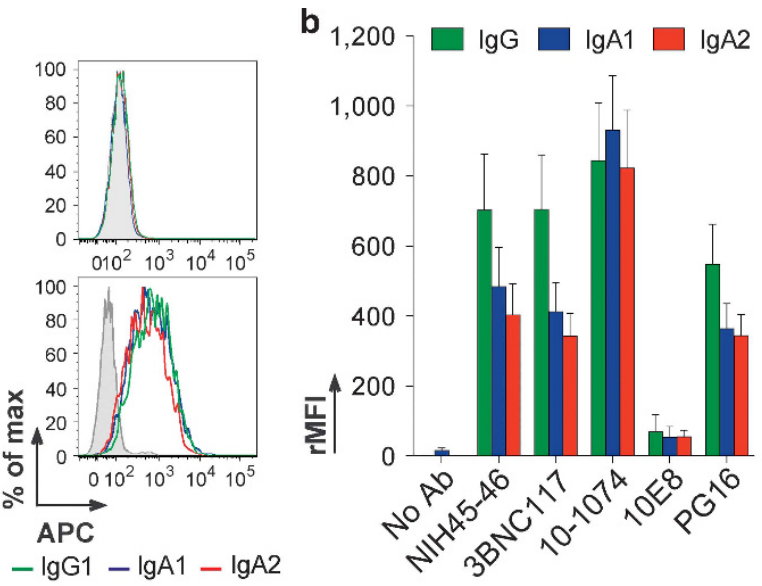

d
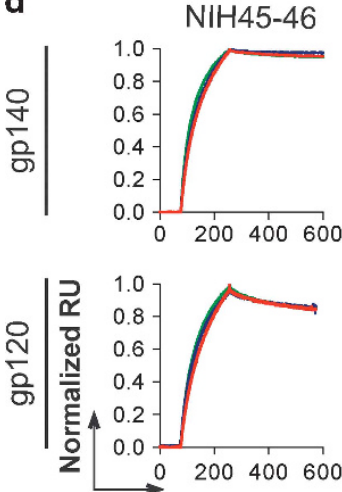

Time (s) $-\lg \mathrm{G} 1-\lg \mathrm{A} 1-\lg \mathrm{A} 2$

$10-1074$
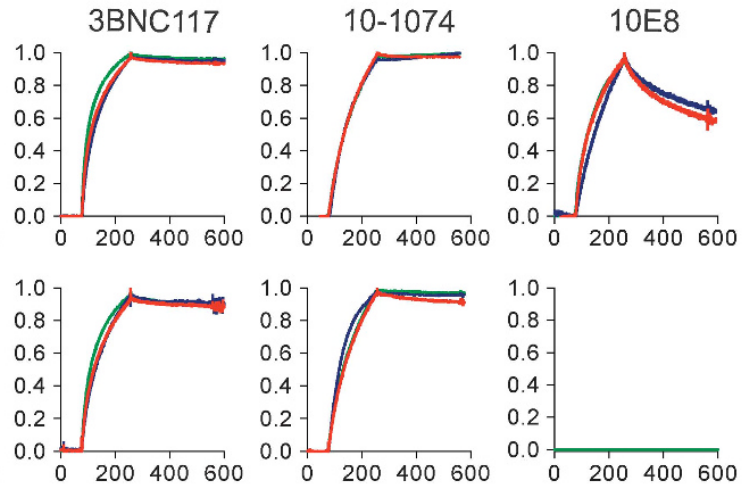

C
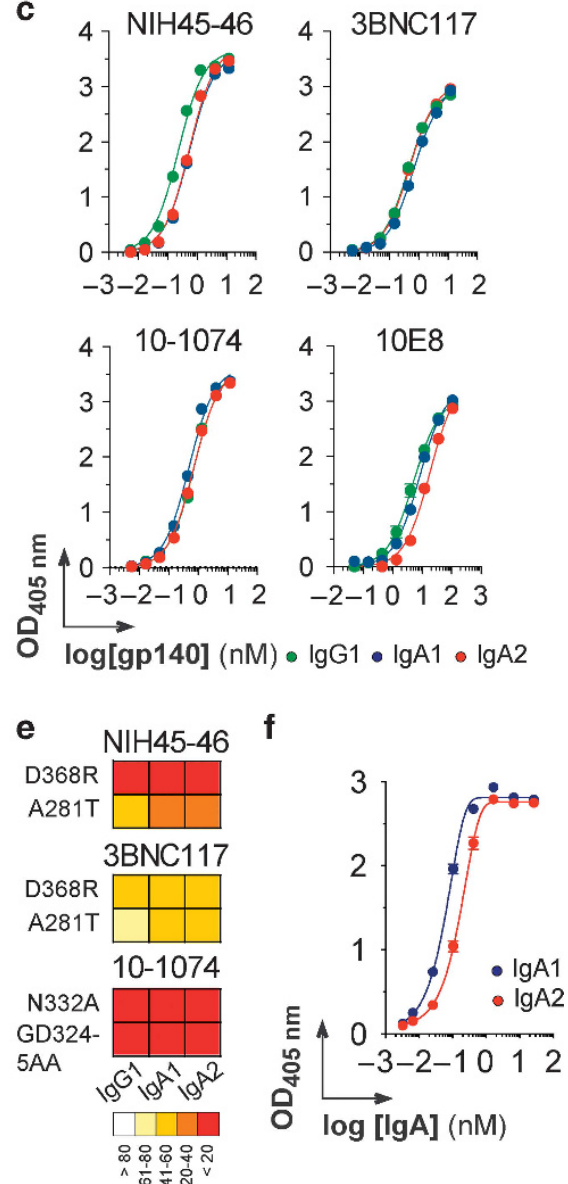

Figure 1 IgA class switching of HIV-1 bNAbs. (a) Cytograms show the binding of 3BNC117 IgG1 (green), IgA1 (blue), and IgA2 (red) antibodies (as examples) to uninfected MT4C5 T cells (upper part), and to $\mathrm{Gag}^{+}$(PE) MT4C5 cells infected with the NLAD8 viral strain (bottom part). (b) Bar graph shows the binding of the selected bNAbs expressed as IgG1 (green), IgA1 (blue), and IgA2 (red) to Gag + infected MT4C5 cells. Horizontal bars represent the relative mean fluorescence intensity (rMFI). Error bars indicate the s.e.m. of triplicate values from two independent experiments. (c) ELISA graphs comparing the binding of YU-2 gp140 to IgG1 (green), IgA1 (blue), and IgA2 (red) bNAbs. The $x$-axis shows the gp140 concentration (nM) required to obtain the ELISA values $\left(\mathrm{OD}_{405 \mathrm{~nm}}\right)$ indicated on the $y$-axis. Error bars indicate the s.e.m. of duplicate values. (d) SPR sensorgrams showing the binding of bNAbs expressed as IgG1 (green), IgA1 (blue), and IgA2 (red) to YU-2 gp140 or gp120 ligands expressed as normalized response units (RU) over time. (e) Heat map (expressed as \% binding to wild-type gp120) summarizing the binding of IgG1, IgA1, and IgA2 bNAbs to selected mutant protein antigens (see Supplementary Figure 2 online). Darker colors = stronger inhibition; light colors = moderate inhibition. (f) ELISA graph shows binding of $10 \mathrm{E} 8$ IgA 1 and IgA2 antibodies to MPER peptide. The $x$-axis shows the antibody concentration (nM) required to obtain the ELISA values $\left(\mathrm{OD}_{405 \mathrm{~nm}}\right)$ indicated on the $y$ axis. Error bars indicate the s.e.m. of duplicate values. bNAbs, broadly neutralizing antibodies; ELISA, enzyme-linked immunosorbent assay; Ig, immunoglobulin; MPER, membrane proximal external region; SPR, surface plasmon resonance.

Figure 2 Antiviral properties of HIV-1 IgA bNAbs. (a) Graphs show neutralization curves of the YU-2 viral strain by IgG1 (green), IgA1 (blue), and IgA2 (red) bNAbs (as an example). The dotted horizontal line indicates $50 \%$ neutralization, from which the $\mathrm{IC}_{50}$ value can be derived from the antibody concentration on the $x$-axis. Error bars indicate the s.d. of triplicate measurements. (b) Bar graphs comparing the neutralization potencies (IC ${ }_{50}$ values) of IgA1 and IgA2 vs IgG1 bNAbs (expressed as fold increase or decrease) against a panel of five selected viruses: a, SC422661.8; b, PVO.4; c, CAAN5342.A2; d, THRO4156.18; e, YU-2. Experiments were performed in triplicate. (c) Cytograms show, using NIH45-46 as example, the inhibition of cell-to-cell HIV-1 transmission by IgG and IgA bNAbs as compared to the infection of non-antibody-treated Far-red-stained primary CD4 + target cells (No Ab). NI, non-infected cells control; NVP, nevirapine treated cells control. (d) Graph comparing the inhibitory activity of IgA1 and IgA2 bNAbs against cell-free (dotted lines) and cell-associated (straight lines) infection. (e) Table comparing the inhibitory activity (IC ${ }_{50}$ values calculated from (d)) of IgA1 and IgA2 vs IgG1 bNAbs against cell-free and cell-associated infection, and expressed as fold increase (blue) or decrease (red). bNAbs, broadly neutralizing antibodies; Ig, immunoglobulin. 

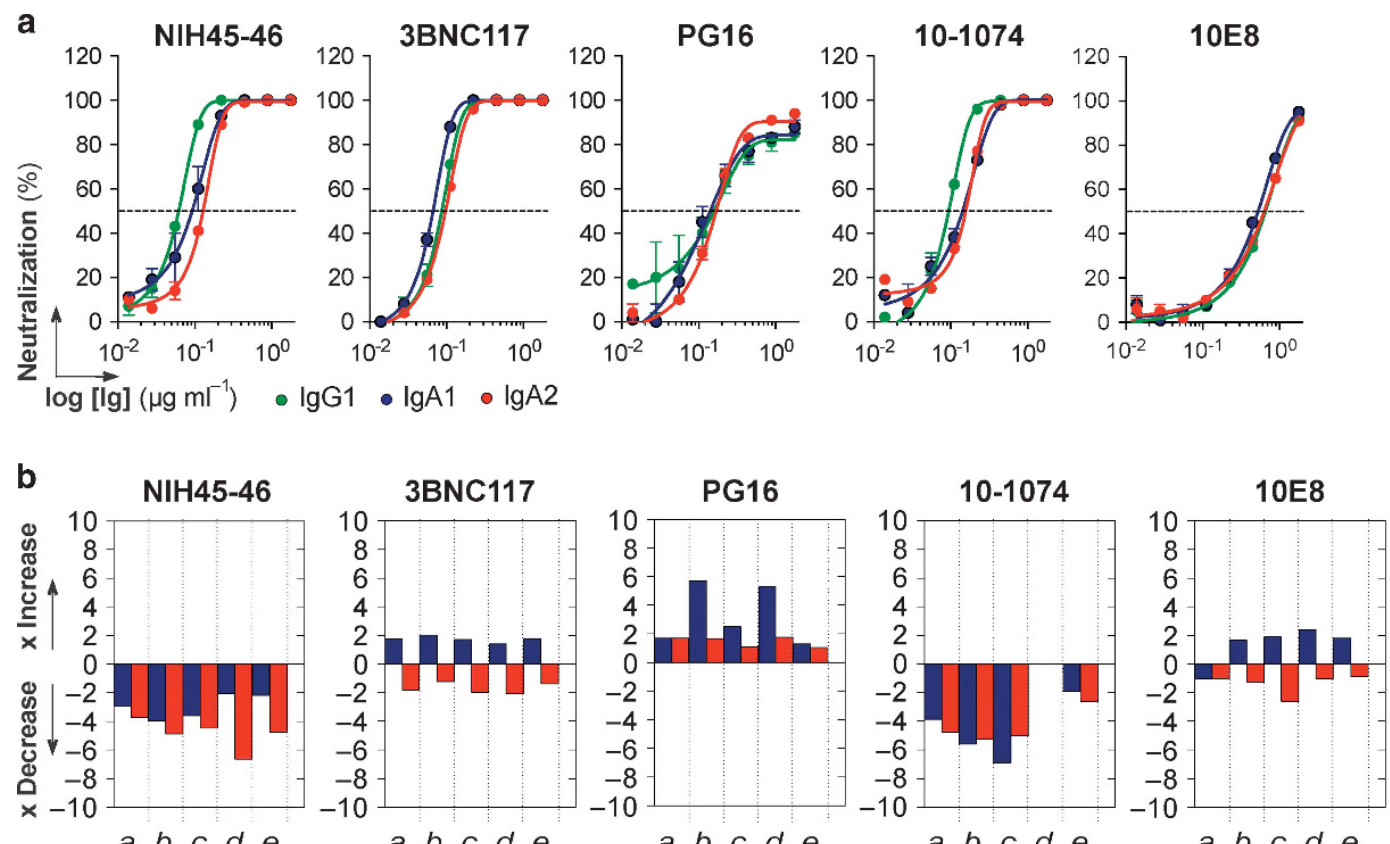

- $\lg \mathrm{A} 1$ vs $\lg \mathrm{G} 1$
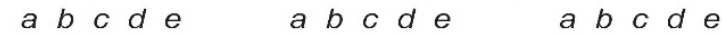

$a b c d e$

C
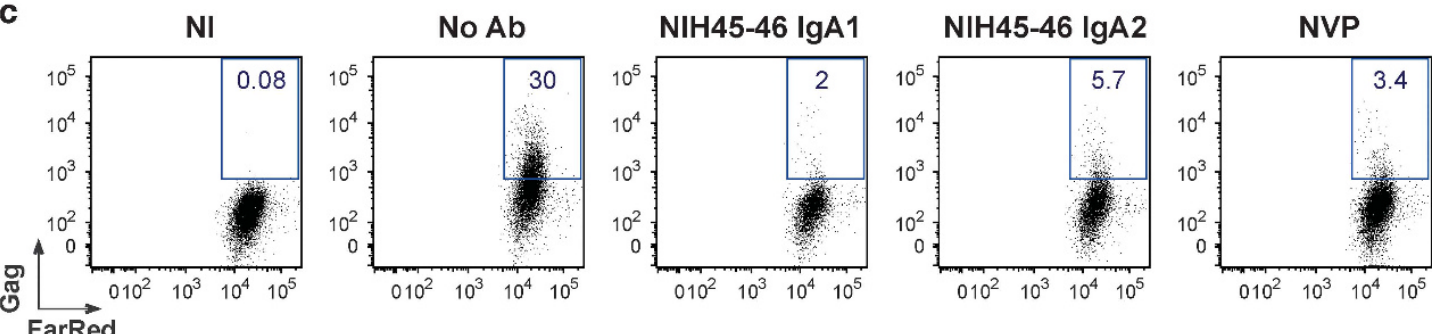

d

d NIH45-46
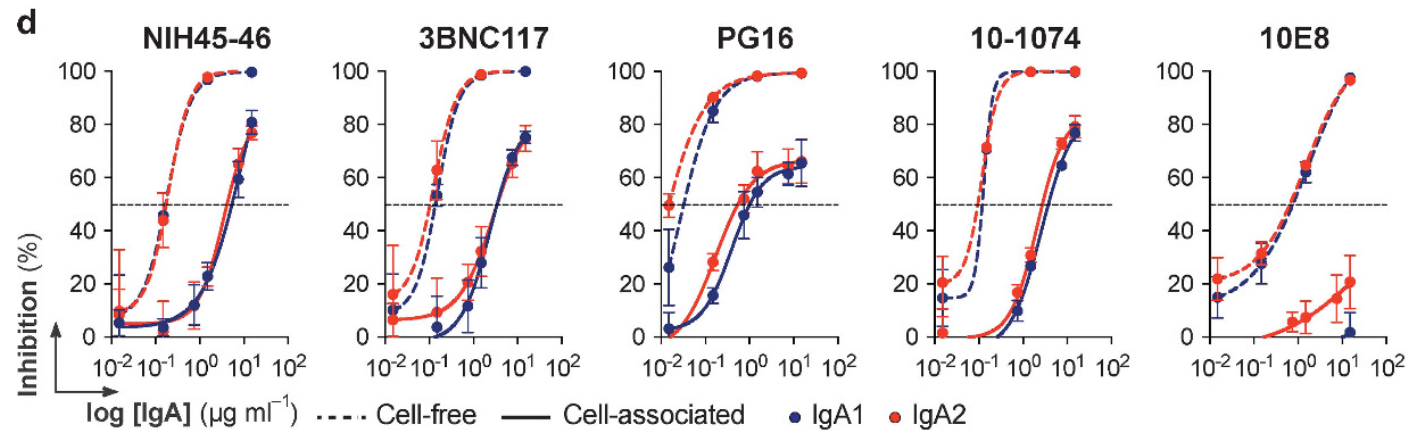

) .... Cell-free

Cell-associated

- $\lg \mathrm{A} 1 \bullet \lg \mathrm{A} 2$

e

Cell-free

Cell-associated

\begin{tabular}{|c|c|c|c|c|c|c|c|c|c|}
\hline & \multicolumn{3}{|c|}{$\mid \mathrm{C}_{50}\left(\mu \mathrm{g} \mathrm{mI^{-1 }}\right)$} & \multicolumn{2}{|c|}{ Fold change } & \multicolumn{2}{|c|}{$\mathrm{IC}_{50}\left(\mu \mathrm{g} \mathrm{m} \mathrm{I}^{-1}\right)$} & \multicolumn{2}{|c|}{ Fold change } \\
\hline & $\lg A 1$ & $\lg A 2$ & $\lg G$ & $\lg G: \lg A 1$ & $\lg G: \lg A 2$ & $\lg A 1 \lg A 2$ & $\lg G$ & $\lg G: \lg A 1$ & $\lg \mathrm{G}: \lg A 2$ \\
\hline NIH45-46 & 0.18 & 0.17 & 0.20 & 1.04 & 1.10 & $5.40 \quad 4.20$ & 2.50 & 2.30 & 1.79 \\
\hline 3BNC117 & 0.11 & 0.14 & 0.07 & 1.68 & 2.13 & $3.40 \quad 3.50$ & 1.50 & 2.42 & 2.49 \\
\hline $10-1074$ & 0.06 & 0.07 & 0.10 & 1.56 & 1.34 & $\begin{array}{ll}3.70 & 2.80\end{array}$ & 1.60 & 2.47 & 1.87 \\
\hline $10 \mathrm{E} 8$ & 0.67 & 0.77 & 1.10 & 1.54 & 1.34 & $X$ & $>15$ & $x$ & $x$ \\
\hline PG16 & 0.02 & 0.03 & 0.05 & 2.34 & 1.56 & $0.90^{*} 0.50^{*}$ & ${ }^{*} 0.50^{*}$ & $1.92^{*}$ & $1.07^{*}$ \\
\hline
\end{tabular}


passively traverse epithelial monolayers, we quantified by ELISA the amount of antibodies being transported through HEC-1A cells into the basal chamber. Both NIH45-46 and mGO53 isotype control antibodies were detected in the basal compartment, transcytosed at a similar level in the presence or absence of NLAD8 viruses, and independently of their isotype (either IgG or IgA) (ranging from 0.9 to $1.9 \%$ ) (Figure 3f). Antibody transcytosis occurred at physiologic $\mathrm{pH}$ ( $\mathrm{pH} 7.6$ on average), at the same rate for IgGs and IgAs, and was unaltered in presence of the vesicular acidification inhibitor bafilomycin A1 (data not shown). This suggests that antibody transcytosis was unlikely to be due to the neonatal $\mathrm{Fc}$ receptor $(\mathrm{FcRn})$ expressed on the apical pole of HEC-1A cells, which only binds IgG molecules at acidic $\mathrm{pH}(<6.5)$.

In order to gain insights into HIV-1 and antibody transport through polarized epithelial cell monolayers, we performed confocal microscopy experiments with green fluorescent protein-labeled HIV-1 viruses alone or incubated with NIH45-46 and 3BNC117 IgG, and mGO53 isotype control. After $4 \mathrm{~h}$, viruses and antibodies were visualized inside HEC-1A cell monolayers, but only anti-gp160 antibodies showed co-localization with virions (Figure 3g, Supplementary Figure S3, Supplementary Movies 1-3). Although mostly accumulated in the apical zone, antibody-virus complexes, as well as viruses and antibodies alone, were spread throughout the depth of epithelial cells and were located in the cytoplasm, suggesting entry by endocytosis (Figure $\mathbf{3 h}$, Supplementary Figure S3, Supplementary Movie 4). Quantification of the co-localization events indicated that about 46 and $60 \%$ of total viral particles were associated with NIH45-46 and 3BNC117, respectively ( $v$ s $1.9 \%$ for mGO53, $P<0.0001)$, Figure $3 \mathbf{i}, \mathbf{j})$.

\section{bNAbs do not block in vitro transcytosis of cell-free and cell-associated HIV-1}

Since we observed intracellular fluorescent clusters of HIV-1 with bNAbs by confocal microscopy, we tested the ability of bNAbs to decrease transcytosis of cell-free HIV-1. Surprisingly, none the five bNAbs (expressed as monomeric IgG1 or IgA1 and IgA2) interfered with the passage of HIV-1 (NLAD8 strain) through HEC-1A monolayers (Figure 4a). Increasing the quantity of antibody or decreasing the amount of virus did not impact viral transcytosis (Figure $\mathbf{4 b , c}$ ). As observed with 101074 IgG1 and monomeric IgAs, 10-1074 IgA dimers and multimers had no measurable effect on HIV-1 transcytosis (Figure 4d). Similarly, all bNAbs tested as IgGs were ineffective at preventing transcytosis of two other HIV-1 strains, YU-2 (Figure 4e) and NL4.3 (Figure 4f).

HIV-1 transcytosis mediated by the formation of a "viral synapse" between infected blood mononuclear cells and epithelial cells is thought to be more efficient than transcytosis with free virions, and can also be blocked by gp160-specific antibodies. ${ }^{12,16,45-47}$ We therefore used human T lymphoblastic cells chronically infected with NL4.3 as a source of HIV-1. As observed with cell-free virions, none of the
IgG bNAbs inhibited cell-associated HIV-1 transcytosis (Figure 4f).

HIV-1 can cross human intestinal epithelial barriers in vivo and in vitro. Thus, we next performed a series of transcytosis experiments using colonic adenocarcinoma cell lines, T84 and Caco-2. ${ }^{48,49}$ As for HEC1-A cells, viral transcytosis across intestinal cell monolayers was unaffected by the absence of envelope glycoproteins (data not shown), and was not inhibited by IgG bNAbs (Figure $\mathbf{4 g - i}$ ).

\section{bNAbs potently inhibit infectivity of transcytosed HIV-1}

We next evaluated whether HIV-1 bNAbs could alter the infectivity of transcytosed viruses. We harvested virus-containing basal medium following transcytosis of HIV-1 in the presence or absence of bNAbs, and tested for viral infectivity using TZM-bl reporter cells after normalizing viral input by $\mathrm{p} 24$ content. The bNAbs NIH45-46, 3BNC117, and 10-1074 induced on average a 1.6-2 log drop of NLAD8 infectivity whereas 10E8 and PG16 were less potent with a 0.9-1.6 log decrease (Figure 5a). Consistent results were obtained with transcytosed YU-2, whose infectivity was inhibited by $0.5-1.7$ $\log$ in the presence of $10 \mathrm{E} 8$ and $3 \mathrm{BNC} 117 \mathrm{IgG}$, respectively (Figure 5b). The effect was dose-dependent, as assessed with 2F5 IgG bNAb (Figure 5c). To determine $\mathrm{IC}_{50}$ values of NLAD8 neutralization by 3BNC117 and 10-1074 following in vitro transcytosis, we tested IgG and IgA bNAbs across a broad concentration range. As expected, viral transcytosis was not impacted regardless of the antibody amount used (Figure 5d). As observed for $2 \mathrm{~F} 5$, post-transcytosis neutralization mediated by $3 \mathrm{BNC} 117$ and 10-1074 was dependent on antibody concentration (Figure 5d). Interestingly, $\mathrm{IC}_{50}$ values determined in the traditional neutralization assay and after viral transcytosis were comparable, with only a 1.4-2.3 and 0.51.7-fold difference for IgG and IgA, respectively (Figure 5e). Finally, NLAD8 infectivity was also dramatically decreased in the presence of $\operatorname{IgG}$ bNAbs following viral transcytosis across T84 and Caco-2 cell monolayers (Figure 5f).

\section{DISCUSSION}

To achieve sterilizing immunity at mucosal sites, antibodies must prevent entry and/or block viral infectivity. Transcytosis is one of the putative mechanisms by which HIV-1 could traverse epithelial barriers following sexual transmission. Compelling evidence on the role of HIV-specific antibodies from both sera and mucosal secretions from HIV-infected patients $^{12,13,50}$ and HEPS individuals ${ }^{14}$ in preventing viral transcytosis in vitro have accumulated over the past 20 years. Similar observations were made using human gp160-reactive monoclonal antibodies derived from HEPS $^{16}$ and HIVseropositive individuals. ${ }^{51-53}$ Nevertheless, whether antigp160 antibodies can truly interfere with HIV-1 transcytosis is still a matter of debate.

In this study, we tested the capacity of potent bNAbs to inhibit HIV-1 transcytosis in a well-established in vitro system using HEC-1A cell monolayers. If induced by a vaccine, these types of antibodies could be transudated in the lumen as IgG 


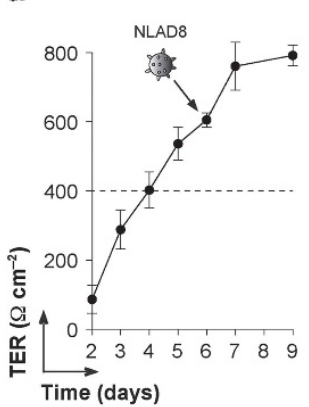

b

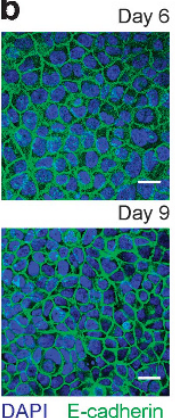

c

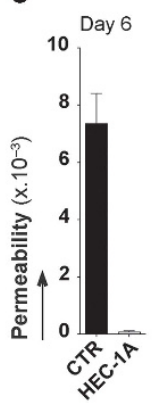

d

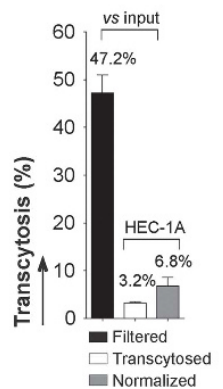

e

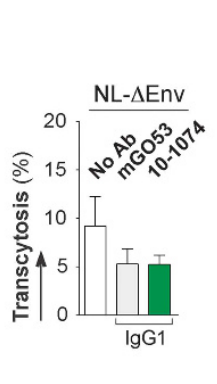

g

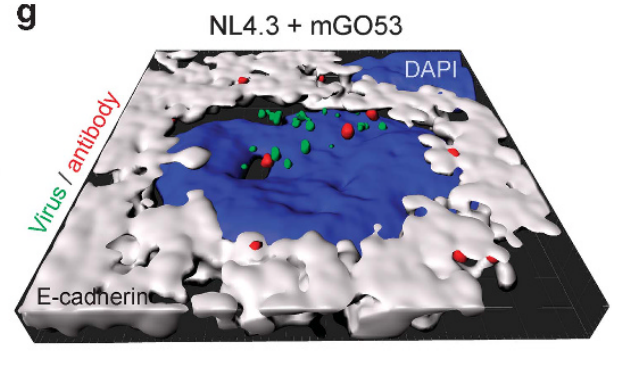

f
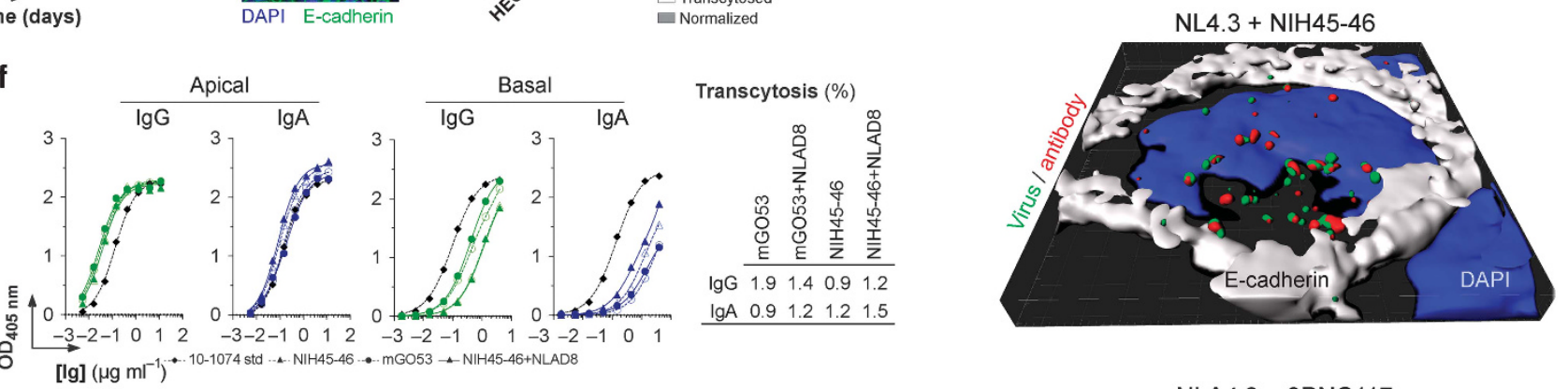

$[\mathrm{lg}]\left(\mu \mathrm{g} \mathrm{ml}^{-1}\right) \cdots 10-1074 \mathrm{std} \cdots \mathrm{A} \cdot \mathrm{NIH} 45-46 \cdots \mathrm{mGO53} \rightarrow \mathrm{NIH} 45-46+\mathrm{NLAD8}$
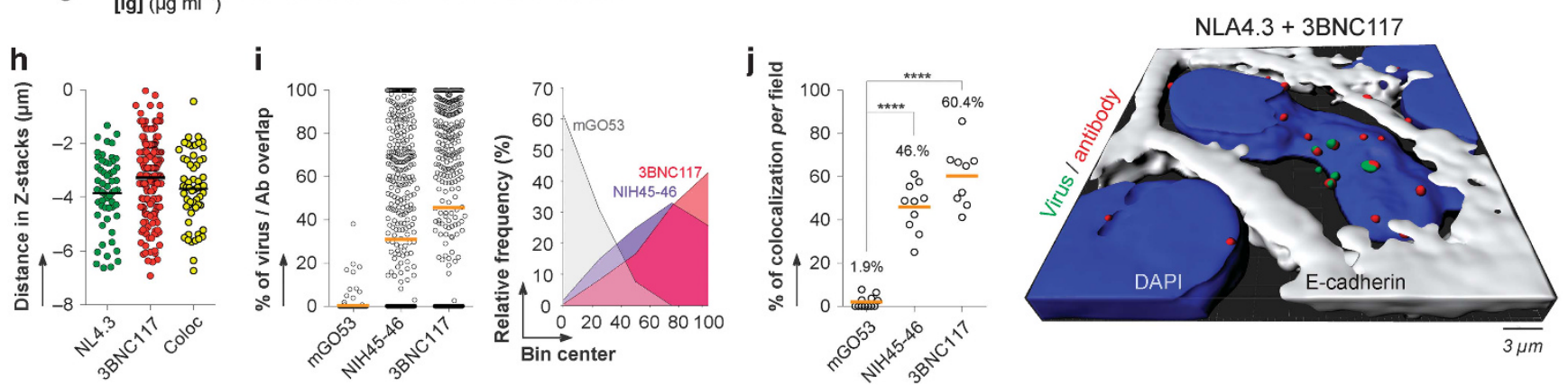

Figure 3 In vitro transcytosis of HIV-1 and bNAbs. (a) Graph shows the transepithelial electrical resistance (TER) values of HEC-1A epithelial cell monolayers according to time of culture. Mean values \pm s.e.m. of two representative experiments (in duplicate) are shown. Transcytosis experiments were performed at day 6 (virus and black arrow). Dotted line indicates the threshold $\left(400 \mathrm{Ohms} \mathrm{cm}{ }^{-2}\right.$ ) to obtain monolayer confluence and integrity of cells. (b) Immunofluorescence staining of HEC-1A monolayers with DAPI and anti-human E-cadherin antibody at day 6 and 9 of culture. Representative images are shown. Scale bar indicates $10 \mu \mathrm{m}$. (c) Bar graph comparing the diffusion of FITC-labeled DEAE-dextran molecules to the basal compartment when passing through the transwell membrane (CTR, control) and the HEC-1A cell monolayer at day 6 . Mean values \pm s.e.m. of two representative experiments (in duplicate) are shown. (d) Bar graph shows the percentage of cell-free virus detected in the basal compartment compared to the input placed in the apical part of the transwell in presence of HEC-1A cells monolayer (transcytosed) or not (filtered). The gray bar corresponds to values for NLAD8 transcytosis (as a percentage of transcytosed viruses) normalized by the filtered virus amount. Mean values \pm s.e.m. of four representative experiments (in triplicate) are shown. (e) Bar graph shows the normalized transcytosis of NL- $\Delta$ Env alone, and in presence of anti-gp120 10-1074 IgG1 (green) and non-HIV-1 reactive mGO53 control lgG1 (gray) antibodies. Mean values of duplicate obtained in three independent experiments are shown. Error bars indicate the s.e.m. Groups were compared to mGO53 negative control using Mann-Whitney test. ns, not significant. (f) Graphs show the ELISA detection post-transcytosis of IgG (green) and IgA (blue) antibodies in the apical and basal compartments. Error bars indicate the s.d. of duplicate measurements. Table in the right-hand side indicates the calculated percent of antibody transcytosis for mGO53 and NIH45-46 IgG and IgA antibodies. (g) Representative images corresponding to the 3D-reconstruction of the confocal microscopy experiments made on HEC-1A cell monolayers with GFPlabeled HIV-1 (green) in presence of MGO53, NIH45-46 or 3BNC117 (red). Nuclei and intercellular junctions were stained with DAPI (blue) and anti-Ecadherin antibody (gray), respectively. (h) Dot plot shows the number of fluorescent objects corresponding to HIV-1 alone (NL4.3), 3BNC117 IgG alone and virus-antibody complexes (Coloc) according to the distance across the Z-stack depth. Quantification was made using one representative $6 \mu \mathrm{m}$ Z-stack acquisition. (i) Graphs show the percentage of overlap between fluorescent HIV-1 and antibodies (left-hand side), and calculated relative frequency according to bin center (right-hand side). Quantification was made using 9-12 different $2 \mu \mathrm{m}$ Z-stack acquisitions per condition (field). (j) Dot plot shows the percentage of colocalization between virus and antibodies calculated from (i). ${ }^{* \star * *} P$ value $<0.0001$ (Mann-Whitney test). bNAbs, broadly neutralizing antibodies; DAPI, 4,6-diamidino-2-phenylindole; DEAE, diethylaminoethyl; Ig, immunoglobulin; ELISA, enzyme-linked immunosorbent assay; GFP, green fluorescent protein.

and/or locally produced IgA molecules. For this reason, we produced selected bNAbs as recombinant IgG and IgA1/IgA2 monoclonal antibodies. In contrast to what was reported in previous works, ${ }^{46,54,55}$ we showed that swapping the bNAbs' Fc region from IgG to IgA did not substantially modify or alter their affinities, targeted epitopes or antiviral inhibitory activities. When applied with or without virus at the surface of the epithelial monolayers, we observed that a similar fraction of purified IgG and IgA was transported to the basal pole, likely in a FcRn-independent manner. As expected, a small proportion of HIV-1 virions ( $\sim 3.5 \%$ of viral inoculum) transcytosed across HEC1-A epithelial cells in vitro. ${ }^{42,45}$ Although the role of envelope glycoproteins for mediating viral endocytosis was disputed, ${ }^{42-44,56,57}$ our experiment clearly demonstrated that 

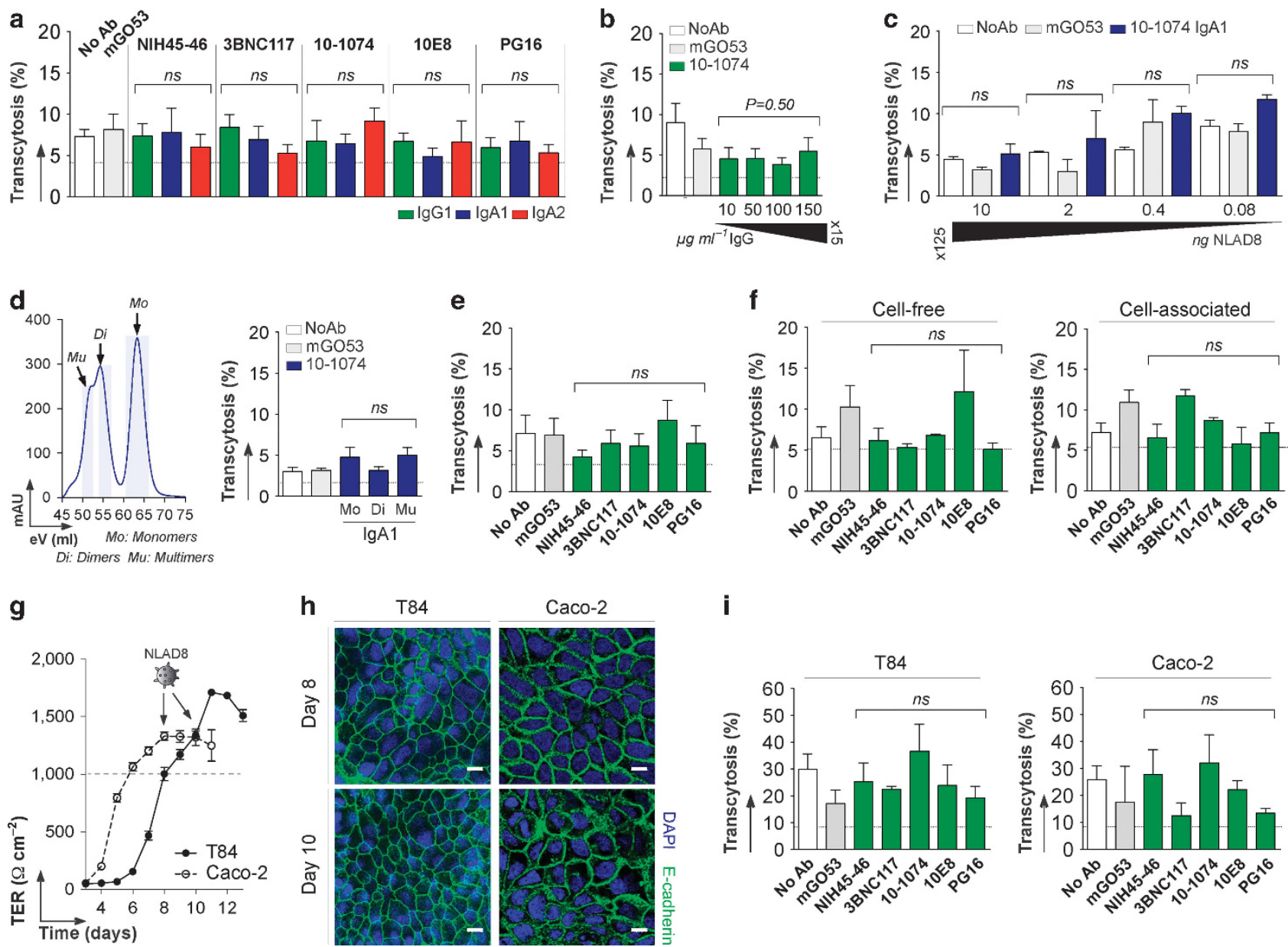

i
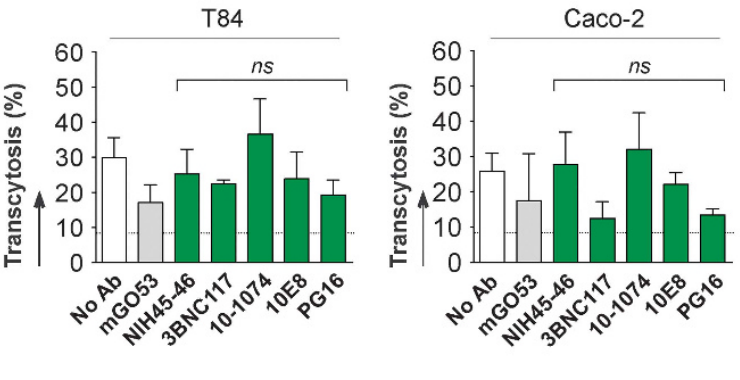

Figure 4 HIV-1 transcytosis in presence of bNAbs. (a) Bar graph shows the percent of transcytosis of NLAD8 alone (No Ab, white), in presence of nonHIV-1 mGO53 control (gray) and selected bNAbs expressed as monomeric IgG1 (green), IgA1 (blue), and IgA2 (red) antibodies. Dotted line indicates an arbitrary threshold corresponding to a twofold decrease of the values obtained with mGO53 control antibody. Mean values $\pm s$.e.m. of three to five independent experiments performed in duplicate are shown. (b) Bar graph shows the percent of transcytosis as in (a) but with increasing amount of 10-1074 IgG antibodies. Mean values \pm s.e.m. of three independent experiments performed in duplicate are shown. (c) Bar graph shows the percent of transcytosis as in (a) for 10-1074 IgA1 but with decreasing amount of NLAD8 virus used as input (as indicated above bars). Mean values of duplicate are shown. Error bars indicate the s.e.m. (d) Bar graph shows the percent of transcytosis as in (a) but with virus in presence of monomeric (Mo), dimeric (Di) and multimeric (Mu) 10-1074 IgA1 antibodies. Mean of triplicate values are shown. Error bars indicate the s.e.m. On the left-hand side, FPLC chromatogram shows the protein separation of IgA monomers, dimers, and multimers by size exclusion chromatography. The $x$-axis shows the elution volume (eV) required to obtain the values of absorption units at $280 \mathrm{~nm}(\mathrm{mAU})$ indicated on the $y$-axis. Light blue bars indicate selected fractions. (e) Bar graph shows the percent of transcytosis of as in (a) but using YU-2 viral strain. Mean values \pm s.e.m. of four independent experiments performed in duplicate are shown. (f) Bar graphs show the percent of transcytosis as in (a) but using cell-free and cell-produced NL4.3 viruses. Mean values \pm s.e.m. of two independent experiments performed in duplicate are shown. (g) Graph shows the TER values of T84 and Caco-2 epithelial cell monolayers according to time of culture. Mean values \pm s.e.m. of three independent experiments (more than 50 transwells in total) are shown. Transcytosis experiments were performed at days 8 and 10

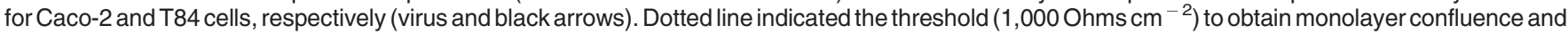
integrity of cells. (h) Immunofluorescence staining of T84 and Caco-2 monolayers with DAPI and anti-human E-cadherin antibody at days 8 and 10 of culture. Representative images are shown. Scale bar indicates $20 \mu \mathrm{m}$. (i) Bar graph shows the percent of transcytosis of as in (a) but using T84 and Caco-2 monolayers and IgG bNAbs only. Mean values \pm s.e.m. of two independent experiments performed in triplicate are shown. Groups were compared to mGO53 negative control using Mann-Whitney test for all except (b), and using one-way ANOVA test for (b). ANOVA, analysis of variance; bNAbs, broadly neutralizing antibodies; FPLC, fast protein liquide chromatography; Ig, immunoglobulin; ns, not significant; TER, transepithelial electrical resistance.

wild-type and envelope-deficient viruses translocated into the basal compartment at equal rates. Therefore, HIV-1 spike interactions with epithelial cell surface receptors may not be required for transcytosis as shown by others. ${ }^{43,44,57}$ Considering that transcytosis is a phenomenon occurring independently of HIV-1 envelope glycoproteins, we asked whether viruses in complex with antibodies still penetrate and cross the epithelia. We found that high concentrations of diverse bNAbs expressed as either monomeric $\operatorname{IgG}, \operatorname{IgA} 1$, or $\operatorname{Ig} \mathrm{A} 2$ were inefficient at blocking transcytosis of cell-free $\mathrm{X} 4$ - and R5-tropic as well as cell-associated viruses. This observation is in accordance with previous works reporting the inability of non-neutralizing and first generation bNAbs to inhibit in vitro HIV-1 transcytosis. ${ }^{42,49}$ Furthermore, we did not observe any superior inhibitory effect of dimeric/polymeric over monomeric IgA1 as previously shown for $2 \mathrm{G} 12$ and anti-gp41 antibodies 2F5 and HGN194. ${ }^{51-53}$ Importantly, no mechanistic evidence has yet been produced showing that dimeric IgAs in complex with virions form large "aggregates" that lead to blocking HIV-1 entry at mucosal sites as hypothesized by others. ${ }^{58}$ It is 

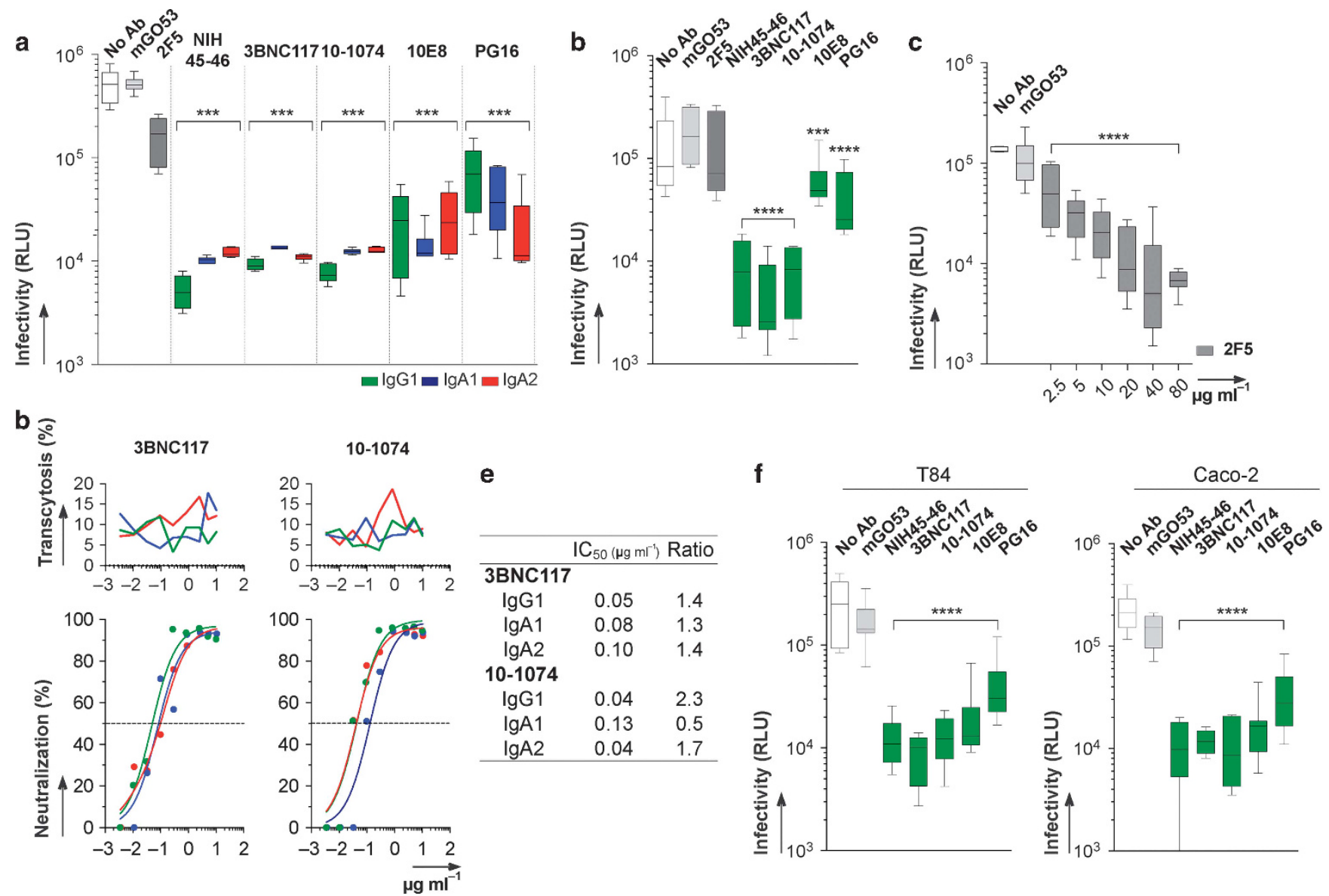

Figure 5 Infectivity of transcytosed HIV-1. (a) Scatter plot shows the infectivity of transcytosed NLAD8 alone (No Ab, white), in presence of non-HIV-1 mGO53 control (light gray), 2F5 IgG1 bNAb (dark gray) and selected bNAbs expressed as monomeric IgG1 (green), IgA1 (blue), and IgA2 (red) antibodies on TZM-bl reporter cells. Antibodies were tested at a final concentration of $66.7 \mathrm{~nm}$ (originating from experiments in Figures 4a). (b) Same as in (a) but with IgG1 bNAbs only in contact with YU-2 viruses used as viral input for transcytosis. (c) Same as in (a) but with increasing concentration of $2 \mathrm{~F} 5$ IgG antibodies (from 2.5 to $80 \mu \mathrm{g} \mathrm{ml}^{-1}$ ) in contact with NLAD8 virions. (d) Upper graph shows the percent of transcytosis of 3BNC117 and 10-1074 IgG1 (green), IgA1 (blue), and IgA2 (red) bNAbs tested across a large concentration range (from 0.023 to $66.7 \mathrm{~nm}$ ). Mean values \pm s.e.m. of duplicate data are shown. Lower graph shows the percent of post-transcytosis neutralization of 3BNC117 and 10-1074 IgG1, IgA1, and IgA2 antibodies as tested above. (e) Table indicating $\mathrm{IC}_{50}$ values obtained after viral transcytosis (left), and calculated ratios (right) comparing them to $I C_{50}$ values determined using the traditional neutralization assay. (f) Same as in (a) but with IgG1 bNAbs only in transcytosis assays using T84 and Caco-2 epithelial cell monolayers. Data represent mean of triplicate values obtained for each transcytosis point performed as shown in Figure 4. Error bars indicate the s.e.m. Groups were compared to mGO53 negative control using Mann-Whitney test for all except (c), and using one-way ANOVA test for (c). ${ }^{* \star \star} P<0.001 ;{ }^{* \star * \star} P<0.0001$. ANOVA, analysis of variance; bNAbs, broadly neutralizing antibodies; Ig, immunoglobulin; ns, not significant.

possible, however, that through interaction of IgG/IgA with gelforming mucin glycoproteins in vivo, HIV-antibody complexes get trapped in mucus layers, ${ }^{59,60}$ and subsequently get washed out by draining, genital secretions. The inefficacy of potent bNAbs in diminishing viral transepithelial migration is on the other hand, contrasting with the blocking capacity on transcytosis that was previously reported for some gp160specific antibodies, especially for IgAs. ${ }^{12,16,46,51-53,61}$ Although the reason(s) for this discordance remain unclear, we demonstrate here that a large proportion of intracellular virions $(\sim 50-60 \%)$ were co-localized with antibodies in the cytoplasm of epithelial cells. Importantly, this observation provides a mechanistic explanation of why anti-gp160 IgG and IgA molecules were not interfering with viral transcytosis; HIV-1 in complex with high affinity immunoglobulins are not sequestered at the surface of the epithelium but instead, enter epithelial cells and migrate to reach the basal cellular pole to be released. The identification of the molecular processes for immune complex entry and transit will demand further investigation, but it appears from our data that the uptake of antibody-coated virions by epithelial cells does not involve the FcRn or the polymeric Ig receptor (not binding IgGs and expressed only at the basal pole of HEC-1A cells ${ }^{62}$.

Subsequent to their translocation through epithelial cells, free HIV-1 virions were still infectious. Because antibodies were incapable of inhibiting viral transcytosis, preventing mucosal transmission would require direct neutralization of free particles and/or Fc-dependent antiviral activity against infected cells such as antibody-dependent cellular cytotoxicity, ${ }^{63}$ and macrophage- and neutrophil-mediated phagocytosis. ${ }^{64}$ Notably, bNAbs could efficiently decrease infectivity of transcytosed viruses suggesting that these antibodies remain associated with HIV-1 during trafficking, ${ }^{49}$ or bind to the virions after their transport to the basal pole. We measured equivalent $\mathrm{IC}_{50}$ values of 
the bNAbs in a traditional neutralization assay and with transcytosed viruses. With a few bNAbs tested in a human mucosa explant model, the neutralization potency correlated with the magnitude of reduction for HIV-1 replication and ex vivo mucosal HIV-1 transmission. ${ }^{65}$ Whether some neutralization events take place intracellularly such as in endosomal vesicles as previously reported ${ }^{13,66}$ still remains to be investigated.

Our data provide a mechanistic explanation of how modest titers of potent bNAbs confer protection against SHIV mucosal challenges in infected macaques. ${ }^{19,20,67,68}$ Following systemic passive administration in vivo, IgG bNAbs diffuse in plasma, distribute rapidly in various tissues including mucosa, ${ }^{68,69}$ and via $\mathrm{FcRn}$ interactions and/or passive diffusion can be translocated into the lumen where they most likely do not block viral transcytosis but may neutralize inoculated infectious virions before their entry into mucosal tissues. In this regard, engineering bNAbs for enhanced binding to FcRn clearly ameliorated their half-lives in vivo and consequently, considerably improved their protective effect in non-human primate models for HIV-1 infection. ${ }^{70,71}$

In summary, our results indicate that HIV-1 antibodies targeting various neutralizing gp 160 epitopes do not block viral transcytosis in human mucosal epithelia. Rather, HIV-1 virions in complex with high affinity IgG or IgA can penetrate epithelial cells, and translocate to be released at the basal pole. However, viruses that are transcytosed in the presence of potent bNAbs are no longer infectious. This phenomenon presumably represents one of the mechanisms by which highly active bNAbs prevent infection in non-human primates challenged at mucosal sites. Understanding the processes involved in preventing HIV-1 mucosal transmission by bNAbs is essential for optimizing antibody-mediated immunotherapies and developing adequate vaccine strategies.

\section{METHODS}

Antibodies and HIV-1 antigens. HIV-1 gp160-specific antibodies $\left(2 \mathrm{~F} 5,{ }^{72} \mathrm{NIH} 45-46,3 \mathrm{BNC} 117,{ }^{37} 10-1074,{ }^{39} 10 \mathrm{E} 8,{ }^{40} \mathrm{PG}^{16} 6^{38}\right)$ and non$\mathrm{HIV}$ mGO53 control antibody ${ }^{73}$ were produced as recombinant IgG monoclonal antibodies and purified as previously described. ${ }^{39,74}$ Each antibody was also produced as recombinant IgA1 and IgA2 molecules using our expression cloning strategy recently described. ${ }^{41}$ Briefly, bNAbs' IgH variable domain $\left(V_{\mathrm{H}}\right)$ genes were cloned into Ig $\alpha 1$ - and $\operatorname{Ig} \alpha 2$-expression vectors using AgeI and SalI restrictions sites. bNAbs IgH vectors with their corresponding IgL expression vectors were then used to co-transfect FreeStyle 293-F cells using the polyethylenimineprecipitation method. ${ }^{41}$ Human IgA monoclonal antibodies were purified by affinity chromatography using either peptide M-coupled agarose (Invivogen, San Diego, CA) or cHB-200-coupled sepharose beads. ${ }^{41}$ The quality of purified $\operatorname{IgA}$ bNAbs was evaluated by SDS-polyacrylamide gel electrophoresis (PAGE) using 4-12\% Bis-Tris Novex gels (Thermo Fisher Scientific, Waltham, MA) in non-reducing conditions followed by a silver staining (Pierce Silver Stain kit, Thermo Fisher Scientific), and immunoblot analysis following protein separation by SDS-PAGE (using $250 \mathrm{ng}$ of IgA), and electrotransfer onto nitrocellulose membranes. Briefly, after a $2 \mathrm{~h}$ saturation step in 5\% dry-milk, $0.05 \%$ Tween 20-Phosphate-buffered saline (PBST), filters were washed with PBST and incubated $1 \mathrm{~h}$ with 1:10,000-diluted goat peroxidase-conjugated anti-human IgA antibodies (Jackson ImmunoResearch, West Grove, PA). After washings, filters were revealed by chemiluminescence reaction (ECL Prime, GE
Healthcare, Chicago, IL), and images were acquired using a G:Box imaging system (Ozyme, Montigny-le-Bretonneux, France). Immunoglobulin polymerization of recombinant IgAs was quantified by size-exclusion chromatography. Briefly, after column equilibration with PBS, IgA1 and IgA2 antibodies $(0.5 \mathrm{mg})$ were injected in a Superdex 200 (Increase 10/300GL, GE Healthcare) at a flow rate of $0.3 \mathrm{ml} \mathrm{min}^{-1}$, and separated using the AKTA pure liquid chromatography system (GE Healthcare) as previously described. ${ }^{41} \mathrm{UV}$ absorbance and conductivity measurements were recorded and analyzed using Unicorn 6.3 software (GE Healthcare). The proportion of multimeric immunoglobulins was calculated using area under the curve values of the specific size-exclusion chromatography pics (compared to the total signal). 10-1074 dimers and multimers were produced by adding J-chain pcDNA3.1/Zeo ${ }^{(+)}$expression vector to the co-transfection reaction, and were fast protein liquide chromatography-purified using cHB-200 gel affinity chromatography followed by size exclusion-based fast protein liquide chromatography. ${ }^{41}$

The production and purification of trimeric gp140, gp120 and mutant proteins were performed as previously described. ${ }^{39,41,75}$ Purified YU-2 gp140 was biotinylated using BirA biotin-protein ligase bulk reaction kit according to the manufacturer's instructions (Avidity LLC, Aurora, CO).

Cells and viruses. Human endometrial carcinoma type A HEC-1A cells (HTB-112, ATCC, Manassas, VA) were cultivated in modified McCoy's 5a medium (Sigma, Saint-Louis, MO). MT4C5 cells, derived from MT4 cells (ATCC) to express CCR5 molecule, ${ }^{76}$ were grown in RPMI 1640 medium (Thermo Fisher Scientific). For both cultures, medium was supplemented with $1 \%$ antibiotic-antimycotic (Thermo Fisher Scientific) and 10\% heat-inactivated fetal bovine serum (FBS) (HyClone, GE Healthcare). TZM-bl cells (\#8129, NIH AIDS Reagent Program, Germantown, MD) were cultivated in 10\% FBS-DMEM (Dulbecco's modified Eagle's medium) supplemented with $1 \%$ penicillin-streptomycin $\left(10,000 \mathrm{U} \mathrm{ml}^{-1}\right.$, Thermo Fisher Scientific) and routinely passaged by treatment with trypsin-EDTA, and with $0.1 \%$ EDTA-PBS before performing the infectivity assay (avoiding proteolysis of CD4 receptors). P4C5 cells ${ }^{77}$ were cultivated in $10 \%$ FBS-DMEM supplemented with $1 \%$ penicillin-streptomycin $\left(10,000 \mathrm{U} \mathrm{ml}^{-1}\right.$, Thermo Fisher Scientific), G418 $\left(500 \mu \mathrm{g} \mathrm{ml}^{-1}\right.$, Sigma) and Hygromycin $\left(50 \mu \mathrm{g} \mathrm{ml}^{-1}\right.$, GE Healthcare). MOLT NL4.3 were grown in RPMI 1640 medium (Thermo Fisher Scientific) supplemented by $1 \%$ penicillin-streptomycin and $10 \%$ heatinactivated FBS. T84 cells (CCL-248, ATCC) were cultivated in DMEM-F12 medium (Thermo Fisher Scientific) supplemented with $10 \%$ heat-inactivated FBS (HyClone, Thermo Fisher Scientific) and 1\% penicillin-streptomycin (10,000 U ml-, Thermo Fisher Scientific). Caco-2 cells (HTB-37, ATCC) were grown in DMEM + Glutamax (Thermo Fischer Scientific) supplemented with $18 \%$ heat-inactivated FBS (HyClone, GE Healthcare). All the cells were cultivated at $37^{\circ} \mathrm{C}$ with $5 \% \mathrm{CO}_{2}$, and medium was renewed every two days for T84 and Caco- 2 cell cultures.

Primary CD $4+$ T cells were purified from human peripheral blood of healthy donors (Etablissement Français du Sang, Rungis, France) by density gradient centrifugation (Ficoll Paque Plus, GE Healthcare) followed by a positive enrichment by magnetic activated cell sorting (MACS) using anti-human CD4-microbeads (Miltenyi Biotec, Bergisch Gladbach, Germany). Primary CD4 $+\mathrm{T}$ cells were then activated by a $24 \mathrm{~h}$ treatment with phytohemagglutinin (PHA, $1 \mu \mathrm{g} \mathrm{ml}^{-1}$, Oxoid, Basingstoke, UK) at $37^{\circ} \mathrm{C}$, and then cultivated for 3-5 days before adding them to interleukin 2 (IL-2)-containing complemented RPMI medium ( $50 \mathrm{IU} \mathrm{ml}^{-1}$, Eurobio-Abcys, Ulis, France). Cells were infected with HIV-1 strains NL4-3, NLAD8, YU-2, and NL4-3 $\Delta$ Env in BSL3 as previously described. ${ }^{78,79}$

Flow cytometry binding analysis to infected cells. MT4C5 cells infected with NLAD8 $(5 \mathrm{ng})$ were incubated with $30 \mu \mathrm{g} \mathrm{ml}^{-1}$ (NIH45-46, 3BNC117, 10-1074, 10E8) or $1 \mu^{-1} \mathrm{ml}^{-1}$ (PG16) of IgG, 
$\operatorname{Ig} \mathrm{A} 1$, and $\operatorname{Ig} \mathrm{A} 2$ antibodies for $1 \mathrm{~h}$ at $37^{\circ} \mathrm{C}$. After two washes with $1 \%$ bovine serum albumin-PBS and centrifugation, cells were stained with 1:400-diluted Alexa 647-conjugated goat anti-human IgG antibodies (Thermo Fisher Scientific) or with purified mouse anti-human IgA HB200 antibodies $\left(30 \mu \mathrm{g} \mathrm{ml}^{-1} \text { final }\right)^{41}$ for $30 \mathrm{~min}$ and $1 \mathrm{~h}$ at $4{ }^{\circ} \mathrm{C}$, respectively. Binding reactions using $\mathrm{HB} 200$ were revealed after washings using 1:400-diluted Alexa 647-conjugated goat anti-mouse IgG antibodies (Thermo Fisher Scientific) for $30 \mathrm{~min}$ at $4{ }^{\circ} \mathrm{C}$. After washes, stained cells were fixed with paraformaldehyde (4\% in PBS) for 5 min and analyzed by flow cytometry (BD FACS Canto II, BD Biosciences, San Jose, CA).

ELISAs. For HIV-1 gp140 trimers binding experiments, high-binding 96-well ELISA plates (Costar, Corning, Corning, NY) were coated overnight with $16.67 \mathrm{~nm}$ of purified IgG1, IgA1, and IgA2 bNAbs in PBS. After washing with $0.05 \%$ PBST, plates were blocked for $2 \mathrm{~h}$ with blocking buffer ( $2 \%$ bovine serum albumin, $1 \mathrm{~mm}$ EDTA, PBST), and then incubated for $2 \mathrm{~h}$ with purified biotinylated YU-2 gp 140 protein at $12 \mu \mathrm{g} \mathrm{ml}^{-1}$ and seven consecutive 1:3 dilutions in PBS. After washings, the plates were developed by incubation with goat horseradish peroxidase-conjugated streptavidin (BD Biosciences) (at $0.5 \mu \mathrm{g} \mathrm{ml}{ }^{-1}$ in blocking buffer) for $30 \mathrm{~min}$, and by addition of $100 \mu \mathrm{l}$ horseradish peroxidase chromogenic substrate (ABTS solution, Euromedex, Souffelweyersheim, France). Optical densities were measured at $405 \mathrm{~nm}\left(\mathrm{OD}_{405 \mathrm{~nm}}\right)$, and background values given by incubation of PBS alone in coated wells were subtracted. All experiments were performed in duplicate and at room temperature using HydroSpeed microplate washer and Sunrise microplate absorbance reader (Tecan, Männedorf, Switzerland). For epitope mapping analyses, all anti-gp160 IgG and IgA antibodies were tested at $26.67 \mathrm{~nm}$ (excepted for NIH45-46 used at $213.3 \mathrm{~nm}$ ) and seven consecutive 1:4 dilutions in PBS by ELISAs as described above using YU-2 gp120, gp $120^{\mathrm{D} 368 \mathrm{R}}, \mathrm{gp} 120^{\mathrm{A} 281 \mathrm{~T}}$, gp $120^{\mathrm{N} 332 \mathrm{~A}}$, and gp120 GD324-5AA purified proteins as antigens (125 ng per well). For each antibody, binding activity against the selected antigens was calculated as area under the best-fit curve (AUC) using GraphPad Prism software (v6.0a), which fits ELISA values $\left(\mathrm{OD}_{405 \mathrm{~nm}}\right)$ according to antibody concentrations using the four-parameter sigmoidal model. Data were expressed as \% AUC compared to wildtype YU-2 gp120. Binding of 10E8 IgG and IgA immunoglobulins to the MPER.03 peptide (NIH AIDS Reagent Program) was tested using a previously described peptide-ELISA method. ${ }^{95}$

To quantify IgG or IgA concentrations in apical and basal media following HIV-1 transcytosis assay, high-binding 96-well ELISA plates (Costar) were coated overnight with $2.5 \mu \mathrm{g} \mathrm{ml}^{-1}$ of goat anti-human IgG (Jackson ImmunoReseach) or $4.0 \mu \mathrm{g} \mathrm{ml}^{-1}$ of mouse anti-human IgA (AbD Serotec, Bio-Rad, Hercules, CA) in PBS. After washing with PBST, plates were blocked for $2 \mathrm{~h}$ with blocking buffer. Prior to primary antibody incubation, viral particles present in both media were first inactivated by heating them for $1 \mathrm{~h}$ at $60^{\circ} \mathrm{C}$ with agitation at $1,400 \mathrm{rpm}$ every $10 \mathrm{~min}$ using a thermomixer (Eppendorf, Hamburg, Germany). Plates were then incubated for $2 \mathrm{~h}$ with inactivated media and seven consecutive 1:3 dilutions in PBS. Purified 10-1074 IgG and IgA1/IgA2 monoclonal antibodies ${ }^{41}$ were used as standards $\left(12 \mu \mathrm{g} \mathrm{ml}^{-1}\right.$ and $4 \mu \mathrm{g} \mathrm{ml}^{-1}$ in PBS for apical and basal medium, respectively). After washings, the plates were developed by incubation for $1 \mathrm{~h}$ with goat horseradish peroxidase-conjugated anti-human IgG or anti-human IgA at $0.5 \mu \mathrm{g} \mathrm{ml}^{-1}$ in blocking buffer (Jackson ImmunoReseach), and by addition of horseradish peroxidase chromogenic substrate as described above. Concentrations were determined by fitting data with the four-parameter sigmoidal model using GraphPad Prism software (v6.0a).

Surface plasmon resonance. All experiments were performed with a Biacore T100 instrument (Biacore, Uppsala, Sweden) in HBS-EP + running buffer (Biacore) at $25^{\circ} \mathrm{C}$ as described previously. ${ }^{80}$ Briefly, YU-2 gp140 and gp120 proteins were primary amine-coupled on CM5 chips (Biacore) at a coupling density of 500 response units. Anti-HIV-1 gp160 bNAbs were injected over flow cells at $0.5 \mu \mathrm{M}$, at flow rates of $40 \mu \mathrm{lmin}{ }^{-1}$ with $3 \mathrm{~min}$ association and $5 \mathrm{~min}$ dissociation phases. The sensor surface was regenerated by a $30 \mathrm{~s}$ injection of $10 \mathrm{~mm}$ glycine$\mathrm{HCl} \mathrm{pH} 2.5$ at a flow rate of $50 \mu \mathrm{min}^{-1}$. All antibodies were tested in at least two independent experiments. Sensorgram data were obtained using the Biacore T100 Evaluation software, and expressed as normalized response units (RU/RUmax) according to the time variable using GraphPad Prism software (v6.0a).

Neutralization assays. Neutralization of cell-free HIV-1 was measured using TZM-bl cells as previously described. ${ }^{81}$ The neutralization activity of bNAbs expressed as $\operatorname{IgG} 1, \operatorname{IgA} 1$, and $\operatorname{IgA} 2$ was also evaluated on P4C5 cells infected with NLAD8 for direct comparison with inhibitory activity values determined in the cell-to-cell HIV-1 transmission assay. One day before infection, $7.0 \times 10^{3}$ P4C5 cells were plated in 96-well plates. Cells were infected in triplicate with $3 \mathrm{ng}$ Gag p24 of NLAD8 virus. Viruses were incubated with purified IgG and IgA bNAbs for $1 \mathrm{~h}$ before infection. After $36 \mathrm{~h}$, cells were lysed in PBS, $0.1 \% \mathrm{NP}-40,5 \mathrm{mM} \mathrm{MgCl}_{2}$ and incubated with the $\beta$-gal substrate CPRG (Roche Molecular Biochemicals, Indianapolis, IN), before measurement of optical densities at $570 \mathrm{~nm}$. Percentage of inhibition was defined as (percent signal in nontreated target cells-percent signal in bNAb-treated cells)/(percent signal in non-treated target cells) $\times 100$. The $50 \%$ inhibitory concentration $\left(\mathrm{IC}_{50}\right)$ values were calculated using GraphPad Prism software (v6.0a) by fitting data from 3 to 6 independent experiments with the sigmoid dose response curves (variable slope) model.

Viral cell-to-cell transmission assay. Viral cell-to-cell transmission assay was performed as previously described. ${ }^{31}$ Briefly, primary donor CD4 + T cells were infected with NLAD8 strain and plated at a final concentration of $1.5 \times 10^{5}$ cells in 24 -well plates. Two days later, when about $10-50 \%$ of the cells were Gag + , primary donor cells were preincubated with the indicated doses of IgG and IgA bNAbs for $1 \mathrm{~h}$, and then mixed with FarRed-labeled target cells at a 1:2 ratio in 96-well plates at a final concentration of $1.5 \times 10^{6} / \mathrm{ml}$ in $200 \mu \mathrm{l}$. After $48 \mathrm{~h}$, cells were stained for intracellular Gag (KC57 mAb, Beckman Coulter, Brea, CA) and analyzed by flow cytometry (BD FACS Canto II, BD Biosciences). When stated, $12.5 \mathrm{~nm}$ Nevirapine (NVP, NIH AIDS Reagent Program) was added $1 \mathrm{~h}$ before coculture.

In vitro viral transcytosis assay. HEC-1A, T84, and Caco-2 monolayer formation was routinely monitored by measuring transepithelial electrical resistance (TER) at the apical and basolateral poles using an epithelial volt-ohm meter (Millicell ERS-2 system, Millipore, Molsheim, Germany). Resistance values of blank filters (without cells) were subtracted from each reading. TER values $>400$ (400-600) Ohms cm ${ }^{-2}\left(\Omega \mathrm{cm}^{-2}\right)$ for HEC1-A and $>1,000(1,000-$ $1,500) \Omega \mathrm{cm}^{-2}$ for T84 and Caco-2 cells were indicative of monolayer confluence, tightness, and integrity. Paracellular permeability of the HEC1-A epithelium was estimated by measuring the transit of FITClabeled diethylaminoethyl-dextran (molecular weight of $40 \mathrm{kDa}$, Molecular Probes, Eugene, OR) as previously described. ${ }^{82}$ Briefly, culture medium was replaced by DMEM without phenol red (Thermo Fisher Scientific). FITC-labeled dextran was added to the upper chamber and filters were sequentially transferred from well to well after 5,10 , and $15 \mathrm{~min}$ of incubation. The quantity of DEAE-dextran molecules diffusing through the monolayer into the basolateral compartment was determined using a fluorescence plate reader (Enspire, Perkin Elmer, Waltham, MA). Permeability coefficients of HEC-1 monolayers were then calculated as previously described. ${ }^{83}$ The expression of tight junction proteins was checked by confocal microscopy using 1:50-diluted anti-E-cadherin antibody-clone 67A4 (Santa Cruz Biotechnology, Dallas, TX), and 1:100-diluted AF647conjugated goat anti-mouse IgG antibodies (Thermo Fisher Scientific), with the same permeabilization conditions as described below. Preparations were examined using the fluorescence microscope TCS Sp5 (Leica, Wetzlar, Germany), and pictures were taken at magnification $\times 63$ at the Imagopole platform (Institut Pasteur, Paris, France). 
Transcytosis assays were conducted using $2.5 \times 10^{4} \mathrm{HEC}-1 \mathrm{~A}$ and T84 cells, and $3 \times 10^{4}$ Caco- 2 cells per transwell to generate a cell monolayer on $0.4 \mu \mathrm{m}$ polyethylene terephthalate membrane hanging cell culture inserts (Millicell, Millipore). Following culture at $37^{\circ} \mathrm{C}$ with $5 \% \mathrm{CO}_{2}$, the transwells with a monolayer displaying TER values ranging from 400 to $600 \Omega \mathrm{cm}^{-}{ }^{2}$ for HEC-1A cells (at day 6), and $1,000-1,500 \Omega \mathrm{cm}^{-2}$ for Caco-2 (at day 8) and T84 (at day 10) cells were used for the transcytosis assay. For T84 and Caco-2 cells, basal and apical media were changed twice during cell culture. HIV-1 viruses (10 ng of p24 HIV-1 cell-free NLAD8, NL4.3, YU-2 or NLAEnv virions in $160 \mu \mathrm{l}$ final volume) were incubated $\mathrm{v} / \mathrm{v}$ for $1 \mathrm{~h}$ at $37^{\circ} \mathrm{C}$ with purified monomeric, dimeric or multimeric antibodies ( $66.67 \mathrm{~nm}$ final concentration), and mixtures were added onto the monolayers. For the cell-associated condition, $6.5 \times 10^{4}$ MOLT NL4.3 cells were mixed v/v with IgG1 bNAbs (with the same final concentration as in cell-free condition) and were added directly without incubation onto the monolayers. This amount of infected cells allowed obtaining the same p24 concentration than in cell-free $\left(62.5 \mathrm{ng} \mathrm{ml}^{-1} \mathrm{p} 24\right.$ antigen in the apical compartment's medium). As controls, HIV-1 alone was added into inserts with cells (No $\mathrm{Ab}$ ) and without cells (CTL) to take into account the proportion of virions that would not pass through the transwell filter. After $24 \mathrm{~h}$ of incubation, media in the upper and lower compartments of the transwells were collected and stored at $-80^{\circ} \mathrm{C}$. Basal media were used to measure p24 concentration and infectivity while lower and upper fluids were used to determine the IgG or IgA concentrations by ELISA. p24 concentration in the lower compartment was determined by ELISA (HIV-1 p24 Antigen Capture Assay, Advanced Bioscience Laboratories, Rockville, MD) according to the manufacturer's instructions. Some transcytosis experiments were performed with: (i) a dose range of NLAD8 virus $(0.08,0.4,2$, and $10 \mathrm{ng}$ p24 HIV-1); (ii) a dose range of purified 10-1074 IgG1 antibody (10, 50,100 , and $150 \mu \mathrm{g} \mathrm{ml}^{-1}$ ); (iii) a pre-treatment with Bafilomycin A1 (Sigma). HEC-1A cell monolayers with TER values $>400 \Omega \mathrm{cm}^{-2}$ were incubated $1 \mathrm{~h}$ with or without $0.1 \mu \mathrm{M}$ Bafilomycin A1 in apical and basal compartments before exposure with NLAD8 alone and antibodies (mGO53 and NIH45-46 expressed as IgG1 and IgA1) plus viruses. After washes with full Mac Coy's medium, transcytosis assay was performed as described above. To calculate the percentage of transcytosis as normalized \% of input, we have used the following formula: (concentration p24 sample/mean concentration p24 $\mathrm{CTL}) \times 100$. Two to five independent experiments (at least in duplicate) were performed except for experiments testing multimeric IgAs and various concentrations of NLAD8 virus.

Cell preparation and confocal microscopy. $1.6 \times 10^{5}$ HEC- $1 \mathrm{~A}$ cells were grown onto coverslips $(12 \mathrm{~mm})$ for 6 days to achieve optimal confluence. NL4.3-Gag-eGFP viruses ${ }^{76}$ (100 ng) were incubated with mGO53 (isotype negative control), NIH45-46 or 3BNC117 IgGs (66.67 nM final concentration) for $1 \mathrm{~h}$ at $37^{\circ} \mathrm{C}$. Mixtures were then applied onto the cells for $4 \mathrm{~h}$ at $37^{\circ} \mathrm{C}$. After washing with PBS, cells were fixed for $10 \mathrm{~min}$ with $4 \%$ paraformaldehyde and then, with $1 \%$ paraformaldehyde before washes in PBS and storage at $4{ }^{\circ} \mathrm{C}$. The intracellular immunostaining was performed after permeabilization of the cells with $0.05 \%$ Saponine (Sigma) in PBS- $1 \%$ bovine serum albumin w/vol- $0.01 \%$ sodium azide buffer. The following antibodies were used for the detection of adhesion junctions and bNAbs: E-cadherin clone 67A4 (1:300) (Santa Cruz Biotechnology), AF647conjugated goat anti-human IgG (1:400) (Thermo Fisher Scientific). Secondary antibody labeled with $\mathrm{Cy} 3$-conjugated goat anti-mouse IgG1 (1:800 final dilution, Jackson Immunoresearch). Between each step, coverslips were washed three times with PBS, and mounted using DAPI-Fluoromount-G (Southern Biotech, Birmingham, AL) before observation.

Z-stack confocal acquisitions were performed on microscope Leica TCS Sp5 with a HCX PL APO $\times 631.4$ N.A. objective in the Imagopole platform (Institut Pasteur). Channel alignments were performed with the tetraSpeck microspheres $0.1 \mu \mathrm{m}$ (Blue/Green/Orange/Dark red;
Thermo Fisher Scientific) to control and correct the chromatic shift. The data were analyzed after chromatic shift and deconvolution with object analyzer advanced modules using Huygens Professional software (v14-10; SVI). For 3D reconstitutions and movies, the Imaris software (v 7.7.2; Bitplane) was used.

In vitro viral infectivity assay. Infectivity of transcytosed free virions in the presence or absence (No Ab) of anti-HIV-1 gp160 IgG/IgA and negative control mGO53 antibodies was measured using TZM-bl cells assay. $1.0 \times 10^{4}$ TZM-bl reporter cells per well in full DMEM containing DEAE-dextran at $8 \mu \mathrm{g} \mathrm{ml}^{-1}$ (final concentration) were incubated for $48 \mathrm{~h}$ at $37^{\circ} \mathrm{C}$ with $0.05 \mathrm{ng}$ of transcytosed virus (recovered from post-transcytosis basal medium volume). Experiments were also performed to evaluate infectivity of NLAD8 transcytosed in the presence of antibodies at concentration ranges of 2F5 IgG (16.67-533.3 nM), 10-1074 and 3BNC117 IgG/IgA (0.023$66.67 \mathrm{nM})$ antibodies. In each experiment, controls were tested in parallel and include: $0.05 \mathrm{ng}$ of NLAD8 virus alone, $0.05 \mathrm{ng}$ of NLAD8 virus in presence of $10-1074$ IgG1 $\mathrm{mAb}\left(20 \mu \mathrm{g} \mathrm{ml}^{-1}\right.$ final concentration) or nevirapine (12.5 $\mu \mathrm{M}$ final concentration). Cells were lysed and the assay developed with Bright-Glo luciferase assay reagent according to the manufacturer's instructions (Promega, Madison, WI). Luminescence signal was measured as relative light units (RLU) using the Enspire microplate luminometer (Perkin Elmer). Each supernatant collected from the transcytosis experiments, when analyzed for neutralization activity, was tested in triplicate. To determine $\mathrm{IC}_{50}$ values for each antibody, we applied the following formula: $100-$ [(RLU mean sample/RLU mean no antibody control) $\times 100]$. Graphs were made by fitting data with non-linear regression with two-site binding hyperbola equation using GrapPad Prism software (v6.0a).

Statistics. Percentages of transcytosis (transcytosis \%) and levels of infectivity were compared for each antibody group to $\mathrm{mGO} 53$ negative control group using Mann-Whitney test. One-way analysis of variance test was used to compare the transcytosis \% in all groups across the 10-1074 IgG concentration range, and the levels of infectivity in all groups across the 2F5 IgG concentration range. Percentages of colocalization events measured by confocal microscopy experiments were compared across groups of antibodies using Mann-Whitney test. Statistical analyses were performed using GraphPad Prism software (v6.0a).

SUPPLEMENTARY MATERIAL is linked to the online version of the paper at http://www.nature.com/mi

\section{ACKNOWLEDGMENTS}

We warmly thank Aaron D. Denahue (Virus \& Immunity Unit) for manuscript editing, Michel C. Nussenzweig and Johannes F. Scheid (Laboratory of Molecular Immunology) for providing us bNAbs expression vectors, Nicoletta Casartelli (Virus \& Immunity Unit), Pierre-Emmanuel Ceccaldi (Oncogenic Virus Epidemiology \& Pathophysiology Unit, Institut Pasteur), and Pascal Roux and Anne Danckaert (Imagopole platform, Institut Pasteur) for their technical advices and/or help on data analyses. We also thank the NIH AIDS Reagent Program for contributing to reagents. O.S. was supported by grants from the ANRS, SIDACTION, the Vaccine Research Institute, the Labex IBEID program, the FP7 program HIT Hidden HIV (Health-F3-2012-305762) and Institut Pasteur. This work was supported by the European Research Council (ERC) - Seventh Framework Program (ERC-2013-StG 337146). H.M. was supported by the ANRS, the G5 Institut Pasteur Program, and the Milieu Intérieur Program (ANR-10LABX-69-01). M.M. was supported by a fellowship from the ERC-2013-StG 337146 Program.

\section{AUTHOR CONTRIBUTIONS}

H.M. conceived the study. V.L., M.M., C.E., T.B., M.S.S., O.S., and H.M. designed, performed, and analyzed the experiments; F.P. and O.S. contributed to reagents; V.L., O.S., and H.M. wrote the manuscript with contributions from all the authors. 


\section{DISCLOSURE}

The authors declared no conflict of interest.

Official journal of the Society for Mucosal Immunology

\section{REFERENCES}

1. Levy, J.A. HIV and the Pathogenesis of AIDS. ASM Press (2013).

2. Xu, H., Wang, X. \& Veazey, R.S. Mucosal immunology of HIV infection. Immunol. rev. 254, 10-33 (2013).

3. Haase, A.T. Early events in sexual transmission of HIV and SIV and opportunities for interventions. Ann. rev. med. 62, 127-139 (2011).

4. Pope, M. \& Haase, A.T. Transmission, acute HIV-1 infection and the quest for strategies to prevent infection. Nat. med. 9, 847-852 (2003).

5. Neutra, M.R. Interactions of viruses and microparticles with apical plasma membranes of $\mathrm{M}$ cells: implications for human immunodeficiency virus transmission. J. infect. dis. 179, S441-S443 (1999).

6. Geijtenbeek, T.B. et al. DC-SIGN, a dendritic cell-specific HIV-1-binding protein that enhances trans-infection of T cells. Cell 100, 587-597 (2000).

7. Haase, A.T. Targeting early infection to prevent HIV-1 mucosal transmission. Nature 464, 217-223 (2010).

8. Shattock, R.J. \& Moore, J.P. Inhibiting sexual transmission of HIV-1 infection. Nat. rev. Microbiol. 1, 25-34 (2003).

9. Bomsel, M. \& Alfsen, A. Entry of viruses through the epithelial barrier: pathogenic trickery. Nat. rev. Mol. cell biol. 4, 57-68 (2003).

10. Kaetzel, C.S. Mucosal immune defense: immunoglobulin A xv, 433 (Springer: New York, 2007).

11. Mouquet, H. Antibody B cell responses in HIV-1 infection. Trends immunol. 35, 549-561 (2014).

12. Alfsen, A., Iniguez, P., Bouguyon, E. \& Bomsel, M. Secretory IgA specific for a conserved epitope on gp41 envelope glycoprotein inhibits epithelial transcytosis of HIV-1. J. immunol. 166, 6257-6265 (2001).

13. Bomsel, M. et al. Intracellular neutralization of HIV transcytosis across tight epithelial barriers by anti-HIV envelope protein dlgA or IgM. Immunity 9 , 277-287 (1998).

14. Devito, C. et al. Mucosal and plasma IgA from HIV-1-exposed uninfected individuals inhibit HIV-1 transcytosis across human epithelial cells. J. immunol. 165, 5170-5176 (2000).

15. Friedman, J. et al. Isolation of HIV-1-neutralizing mucosal monoclonal antibodies from human colostrum. PLoS One 7, e37648 (2012).

16. Tudor, D. et al. HIV-1 gp41-specific monoclonal mucosal IgAs derived from highly exposed but lgG-seronegative individuals block HIV-1 epithelial transcytosis and neutralize CD4 $(+)$ cell infection: an IgA gene and functional analysis. Mucosal immunol. 2, 412-426 (2009).

17. Horwitz, J.A. et al. HIV-1 suppression and durable control by combining single broadly neutralizing antibodies and antiretroviral drugs in humanized mice. Proc. Natl. Acad. Sci. USA 110, 16538-16543 (2013).

18. Klein, F. et al. HIV therapy by a combination of broadly neutralizing antibodies in humanized mice. Nature 492, 118-122 (2012).

19. Moldt, B. et al. Highly potent HIV-specific antibody neutralization in vitro translates into effective protection against mucosal SHIV challenge in vivo. Proc. Natl. Acad. Sci. USA 109, 18921-18925 (2012).

20. Shingai, M. et al. Antibody-mediated immunotherapy of macaques chronically infected with SHIV suppresses viraemia. Nature 503, 277-280 (2013).

21. Barouch, D.H. et al. Therapeutic efficacy of potent neutralizing HIV-1specific monoclonal antibodies in SHIV-infected rhesus monkeys. Nature 503, 224-228 (2013).

22. Hessell, A.J. et al. Broadly neutralizing human anti-HIV antibody $2 \mathrm{G} 12$ is effective in protection against mucosal SHIV challenge even at low serum neutralizing titers. PLoS pathog. 5, e1000433 (2009).

23. Hessell, A.J. et al. Broadly neutralizing monoclonal antibodies 2F5 and 4E10 directed against the human immunodeficiency virus type $1 \mathrm{gp} 41$ membrane-proximal external region protect against mucosal challenge by simian-human immunodeficiency virus SHIVBa-L. J. virol. 84, 1302-1313 (2010).

24. Hessell, A.J. et al. Effective, low-titer antibody protection against low-dose repeated mucosal SHIV challenge in macaques. Nat. med. 15, 951-954 (2009).
25. Moog, C. et al. Protective effect of vaginal application of neutralizing and nonneutralizing inhibitory antibodies against vaginal SHIV challenge in macaques. Mucosal immunol. 7, 46-56 (2014).

26. Mascola, J.R. et al. Protection of macaques against vaginal transmission of a pathogenic HIV-1/SIV chimeric virus by passive infusion of neutralizing antibodies. Nat. med. 6, 207-210 (2000).

27. Balazs, A.B. et al. Vectored immunoprophylaxis protects humanized mice from mucosal HIV transmission. Nat. med. 20, 296-300 (2014).

28. Hur, E.M., Patel, S.N., Shimizu, S., Rao, D.S. \& Gnanapragasam, P.N. An DS et al. Inhibitory effect of HIV-specific neutralizing IgA on mucosal transmission of HIV in humanized mice. Blood 120, 4571-4582 (2012).

29. Caskey, M. et al. Viraemia suppressed in HIV-1-infected humans by broadly neutralizing antibody 3BNC117. Nature 522, 487-491 (2015).

30. Lynch, R.M. et al. Virologic effects of broadly neutralizing antibody VRC01 administration during chronic HIV-1 infection. Sci. transl. med. 7, 319 ra206 (2015).

31. Malbec, M. et al. Broadly neutralizing antibodies that inhibit HIV-1 cell to cell transmission. J. exp. med. 210, 2813-2821 (2013).

32. Bruel, T. et al. Elimination of HIV-1-infected cells by broadly neutralizing antibodies. Nat. commun. 7, 10844 (2016).

33. Bournazos, S., Klein, F., Pietzsch, J., Seaman, M.S., Nussenzweig, M.C. \& Ravetch, J.V. Broadly neutralizing anti-HIV-1 antibodies require Fc effector functions for in vivo activity. Cell 158, 1243-1253 (2014).

34. Halper-Stromberg, A. et al. Broadly neutralizing antibodies and viral inducers decrease rebound from HIV-1 latent reservoirs in humanized mice. Cell 158, 989-999 (2014).

35. Hessell, A.J. et al. Fc receptor but not complement binding is important in antibody protection against HIV. Nature 449, 101-104 (2007).

36. Lu, C.-L. et al. Enhanced clearance of HIV-1-infected cells by broadly neutralizing antibodies against HIV-1 in vivo. Science 352, 1001-1004 (2016).

37. Scheid, J.F. et al. Sequence and structural convergence of broad and potent HIV antibodies that mimic CD4 binding. Science 333, 1633-1637 (2011).

38. Walker, L.M. et al. Broad and potent neutralizing antibodies from an African donor reveal a new HIV-1 vaccine target. Science 326, 285-289 (2009).

39. Mouquet, $\mathrm{H}$. et al. Complex-type N-glycan recognition by potent broadly neutralizing HIV antibodies. Proc. Natt. Acad. Sci. USA 109, E3268-E3277 (2012).

40. Huang, J. et al. Broad and potent neutralization of HIV-1 by a gp41-specific human antibody. Nature 491, 406-412 (2012).

41. Lorin, V. \& Mouquet, H. Efficient generation of human IgA monoclonal antibodies. J. immunol. meth. 422, 102-110 (2015).

42. Chomont, N. et al. Neutralizing monoclonal antibodies to human immunodeficiency virus type 1 do not inhibit viral transcytosis through mucosal epithelial cells. Virology 370, 246-254 (2008).

43. Kinlock, B.L., Wang, Y., Turner, T.M., Wang, C. \& Liu, B. Transcytosis of $\mathrm{HIV}-1$ through vaginal epithelial cells is dependent on trafficking to the endocytic recycling pathway. PLoS One 9, e96760 (2014).

44. Zheng, J. et al. gp120-independent HIV infection of cells derived from the female reproductive tract, brain, and colon. J. acquir. immune defic. syndr. 43, 127-136 (2006).

45. Alfsen, A., Yu, H., Magerus-Chatinet, A., Schmitt, A. \& Bomsel, M. HIV-1infected blood mononuclear cells form an integrin- and agrin-dependent viral synapse to induce efficient HIV-1 transcytosis across epithelial cell monolayer. Mol. biol. cell 16, 4267-4279 (2005).

46. Tudor, D. et al. Isotype modulates epitope specificity, affinity, and antiviral activities of anti-HIV-1 human broadly neutralizing 2F5 antibody. Proc. Natl. Acad. Sci. USA 109, 12680-12685 (2012).

47. Bomsel, M. et al. Immunization with HIV-1 gp41 subunit virosomes induces mucosal antibodies protecting nonhuman primates against vaginal SHIV challenges. Immunity 34, 269-280 (2011).

48. Bomsel, M. Transcytosis of infectious human immunodeficiency virus across a tight human epithelial cell line barrier. Nat. med. 3, 42-47 (1997).

49. Gupta, S. et al. The Neonatal Fc receptor (FcRn) enhances human immunodeficiency virus type 1 (HIV-1) transcytosis across epithelial cells. PLoS pathog. 9, e1003776 (2013). 
50. Hocini, H. et al. High-level ability of secretory IgA to block HIV type 1 transcytosis: contrasting secretory lgA and IgG responses to glycoprotein 160. AIDS res. hum. retroviruses 13, 1179-1185 (1997).

51. Shen, R. et al. GP41-specific antibody blocks cell-free HIV type 1 transcytosis through human rectal mucosa and model colonic epithelium. J. immunol. 184, 3648-3655 (2010).

52. Watkins, J.D. et al. Anti-HIV IgA isotypes: differential virion capture and inhibition of transcytosis are linked to prevention of mucosal R5 SHIV transmission. Aids 27, F13-F20 (2013).

53. Wolbank, S., Kunert, R., Stiegler, G. \& Katinger, H. Characterization of human class-switched polymeric (immunoglobulin M [IgM] and IgA) antihuman immunodeficiency virus type 1 antibodies 2F5 and 2G12. J. virol. 77, 4095-4103 (2003).

54. Yu, X. et al. Impact of IgA constant domain on HIV-1 neutralizing function of monoclonal antibody F425A1g8. J. immunol. 190, 205-210 (2013).

55. Janda, A., Bowen, A., Greenspan, N.S. \& Casadevall, A. Ig constant region effects on variable region structure and function. Front. microbiol. 7, 22 (2016).

56. Bobardt, M.D. et al. Cell-free human immunodeficiency virus type 1 transcytosis through primary genital epithelial cells. J. virol. 81, 395-405 (2007).

57. Carias, A.M. et al. Defining the interaction of HIV-1 with the mucosal barriers of the female reproductive tract. J. virol. 87, 11388-11400 (2013).

58. Zhou, M. \& Ruprecht, R.M. Are anti-HIV IgAs good guys or bad guys?. Retrovirology 11, 109 (2014).

59. Chen, A. et al. Transient antibody-mucin interactions produce a dynamic molecular shield against viral invasion. Biophys. j. 106, 2028-2036 (2014).

60. Fahrbach, K.M., Malykhina, O., Stieh, D.J. \& Hope, T.J. Differential binding of IgG and IgA to mucus of the female reproductive tract. PLoS One 8, e76176 (2013).

61. Mantis, N.J. et al. Inhibition of HIV-1 infectivity and epithelial cell transfer by human monoclonal $\lg \mathrm{G}$ and $\lg \mathrm{A}$ antibodies carrying the b12 $\mathrm{V}$ region. J. immunol. 179, 3144-3152 (2007).

62. Ball, J.M. et al. A polarized human endometrial cell line that binds and transports polymeric IgA. In vitro cell. dev. biol. Anim. 31, 196-206 (1995).

63. Haynes, B.F. et al. Immune-correlates analysis of an HIV-1 vaccine efficacy trial. N. Engl. J. Med. 366, 1275-1286 (2012).

64. Sips, M. et al. Fc receptor-mediated phagocytosis in tissues as a potent mechanism for preventive and therapeutic HIV vaccine strategies. Mucosal immunol. 9, 1584-1595 (2016).

65. Scott, Y.M., Park, S.Y. \& Dezzutti, C.S. Broadly neutralizing anti-HIV antibodies prevent HIV infection of mucosal tissue ex vivo. Antimicrob. agents chemother. 60, 904-912 (2015).

66. Huang, Y.T., Wright, A., Gao, X., Kulick, L., Yan, H. \& Lamm, M.E. Intraepithelial cell neutralization of HIV-1 replication by lgA. J. immunol. 174, 4828-4835 (2005).

67. Pegu, A. et al. Neutralizing antibodies to HIV-1 envelope protect more effectively in vivo than those to the CD4 receptor. Sci. transl. med. 6 , $243 r a 288$ (2014).

68. Shingai, M. et al. Passive transfer of modest titers of potent and broadly neutralizing anti-HIV monoclonal antibodies block SHIV infection in macaques. J. exp. med. 211, 2061-2074 (2014).

69. Hessell, A.J. et al. Early short-term treatment with neutralizing human monoclonal antibodies halts SHIV infection in infant macaques. Nat. med. 22, 362-368 (2016).
70. Gautam, R. etal. A single injection of anti-HIV-1 antibodies protects against repeated SHIV challenges. Nature 533, 105-109 (2016).

71. Ko, S.Y. et al. Enhanced neonatal Fc receptor function improves protection against primate SHIV infection. Nature 514, 642-645 (2014).

72. Muster, T. et al. A conserved neutralizing epitope on gp41 of human immunodeficiency virus type 1. J. virol. 67, 6642-6647 (1993).

73. Wardemann, H., Yurasov, S., Schaefer, A., Young, J.W., Meffre, E. \& Nussenzweig, M.C. Predominant autoantibody production by early human B cell precursors. Science 301, 1374-1377 (2003).

74. Tiller, T., Meffre, E., Yurasov, S., Tsuiji, M., Nussenzweig, M.C. \& Wardemann, $\mathrm{H}$. Efficient generation of monoclonal antibodies from single human B cells by single cell RT-PCR and expression vector cloning. J. immunol. meth. 329, 112-124 (2008).

75. Mouquet, $\mathrm{H}$. et al. Memory B cell antibodies to HIV-1 gp140 cloned from individuals infected with Clade A and B viruses. PLoS One 6, e24078 (2011).

76. Casartelli, N. et al. Tetherin restricts productive HIV-1 cell-to-cell transmission. PLoS pathog. 6, e1000955 (2010).

77. Schwartz, O., Alizon, M., Heard, J.M. \& Danos, O. Impairment of T cell receptor-dependent stimulation in CD4 + lymphocytes after contact with membrane-bound HIV-1 envelope glycoprotein. Virology 198, 360-365 (1994).

78. Lepelley, A. et al. Innate sensing of HIV-infected cells. PLoS pathog. 7, e1001284 (2011).

79. Rudnicka, D. et al. Simultaneous cell-to-cell transmission of human immunodeficiency virus to multiple targets through polysynapses. J. virol. 83, 6234-6246 (2009).

80. Mouquet, $\mathrm{H}$. et al. Polyreactivity increases the apparent affinity of anti-HIV antibodies by heteroligation. Nature 467, 591-595 (2010).

81. Li, M. et al. Human immunodeficiency virus type 1 env clones from acute and early subtype B infections for standardized assessments of vaccineelicited neutralizing antibodies. J. virol. 79, 10108-10125 (2005).

82. Afonso, P.V. et al. Alteration of blood-brain barrier integrity by retroviral infection. PLoS pathog. 4, e1000205 (2008).

83. Dehouck, M.P., Jolliet-Riant, P., Bree, F., Fruchart, J.C., Cecchelli, R. \& Tillement, J.P. Drug transfer across the blood-brain barrier: correlation between in vitro and in vivo models. J. neurochem. 58, 1790-1797 (1992).

(c) (1) () $\Theta$ This work is licensed under a Creative Commons Attribution-NonCommercial-NoDerivs 4.0 International License. The images or other third party material in this article are included in the article's Creative Commons license, unless indicated otherwise in the credit line; if the material is not included under the Creative Commons license, users will need to obtain permission from the license holder to reproduce the material. To view a copy of this license, visit http://creativecommons.org/licenses/by-nc-nd/4.0/

(C) The Author(s) 2017 